\title{
Sex-specific IL-6-associated signaling activation in ozone-induced lung inflammation
}

\author{
Vikas Mishra', Susan L. DiAngelo ${ }^{1}$ and Patricia Silveyra ${ }^{1,2^{*}}$
}

\begin{abstract}
Background: Acute ozone $\left(\mathrm{O}_{3}\right)$ exposure has known deleterious effects on the respiratory system and has been linked with respiratory disease and infection. Inflammatory lung disease induced by air pollution has demonstrated greater severity and poorer prognosis in women vs. men. Both severe damage to the bronchial-alveolar epithelium and malfunctioning of bronchial-blood barrier have been largely attributed to the pathobiology of $\mathrm{O}_{3}$-induced inflammatory response, but the associated mechanisms in the male and female lung remain unknown.

Methods: Here, we investigated sex-based differential regulation of lung interleukin-6 (IL-6) and its downstream signaling pathways JAK2/STAT3 and AKT1/NF-KB in response to $\mathrm{O}_{3}$ exposure in a mouse model. We exposed male and female mice (in different stages of the estrous cycle) to 2 ppm of $\mathrm{O}_{3}$ or filtered air (FA) for $3 \mathrm{~h}$, and we harvested lung tissue for protein expression analysis by Western blot.

Results: We found significant up-regulation of IL- 6 and IL-6R in females and IL-6 in males in response to $\mathrm{O}_{3}$ Vs. FA. Ozone exposure induced a significant increase in STAT3-Y705 phosphorylation in both females and males. Males exposed to $\mathrm{O}_{3}$ had decreased levels of JAK2, but increased JAK2 (Y1007+Y1008) phosphorylation, while females exposed to $\mathrm{O}_{3}$ showed significant up-regulation of both proteins. Both NF-KB (p105/p50) and AKT1 protein levels were significantly increased only in females exposed to $\mathrm{O}_{3}$. In addition, females exposed to $\mathrm{O}_{3}$ during proestrus displayed increased expression of selected genes when compared to females exposed to $\mathrm{O}_{3}$ in other estrous cycle stages.

Conclusions: Together, our observations indicate a sex-based and estrous cycle-dependent differential lung inflammatory response to $\mathrm{O}_{3}$ and involvement of two converging JAK2/STAT3 and AKT1/NF-KB pathways. To our knowledge, this is the first study specifically addressing the impact of the estrous cycle in $\mathrm{O}_{3}$-associated lung inflammatory pathways.
\end{abstract}

Keywords: Inflammation, Oxidative stress, Lung disease, Gender differences, Estrous cycle

\section{Background}

Ground-level ozone $\left(\mathrm{O}_{3}\right)$ is a photochemical air pollutant and a powerful oxidant formed by the action of sunlight on nitrogen oxides and reactive hydrocarbons, both of which are emitted by motor vehicles and industrial sources [1]. Exposure to $\mathrm{O}_{3}$ even within the safe concentration range as per the standard definition by Environmental Protection Agency can affect breathing and lung function and has

\footnotetext{
* Correspondence: pzs13@psu.edu

${ }^{1}$ Department of Pediatrics, The Pennsylvania State University College of Medicine, 500 University Drive, H085, Hershey, PA 17033, USA

${ }^{2}$ Department of Biochemistry and Molecular Biology, The Pennsylvania State University College of Medicine, Hershey, PA 17033, USA
}

deleterious effects on pulmonary innate immunity [2-4]. Acute $\mathrm{O}_{3}$ exposure is toxic to the respiratory system and has been linked with respiratory tract infections, asthma, chronic obstructive pulmonary disease, cystic fibrosis, lung cancer, and cardiovascular disease, with relatively poor prognosis and higher mortality in women than in men [5-11]. Studies point to gender-based differences in incidence, risk, severity, and pathology of certain environmental lung diseases in women as compared to men [12-14]. Growing evidence indicated that females are more susceptible to the toxic effects of tobacco $[15,16]$, have worse respiratory symptoms [17, 18], and higher 
airway responsiveness [19] compared to males. Several studies have proposed circulating hormone levels as potential regulatory factors of immune responses in the female [20-23]. However, the mechanisms associated with the differential lung disease outcomes in men and women are still poorly understood.

Acute $\mathrm{O}_{3}$ exposure and manifestation of clinical respiratory symptoms can primarily be attributed to formation of cytotoxic products and acute cellular injury through oxidative stress, causing biochemical and physiological changes in the lung epithelium. These are mediated by an increased production of reactive oxygen species, accumulation of oxidized biomolecules and activation of inflammatory processes, both locally and systemically $[24,25]$. The pathologic response of acute $\mathrm{O}_{3}$ exposure associated oxidative stress is yet to be completely elucidated. However, investigations indicate a crucial involvement of $\mathrm{O}_{3}$-associated damage to the bronchial-alveolar epithelium as a potential mechanism [26, 27]. Malfunction of the bronchial-alveolar epithelium and bronchial-blood barrier due to loss of integrity of tight junctions may increase immune cell infiltration and inflammatory response. Predominantly, studies have indicated involvement of two groups of markers in $\mathrm{O}_{3}$ pathobiology, the free arachidonic acid and its metabolites [28, 29] and cytokines [30-32]. Cytokines have been implicated as potential mediators of lung oxidative injury [33, 34]. Recent studies have shown induction of acute-phase cytokines including IL-1, IL-2, IL-6, IL-8, and TNF- $\alpha$, as well as the neutrophil chemotactic factors keratinocyte-derived chemokine (KC), MIP-2, and LPS-induced CXC chemokine (LIX), following $\mathrm{O}_{3}$ exposures [30, 35-39]. Many of these secreted factors are recognized downstream products of activation of the innate immune system. These data suggest that downstream activation of pro-inflammatory factors play an important role in response to ambient $\mathrm{O}_{3}$; however, the stimulus leading to activation of these pro-inflammatory factors and their cross-talk remains poorly understood.

Previously, we have reported that exposure of $\mathrm{O}_{3}$ significantly decreased survival of male and female mice after bacterial infection [27]. Infected females exposed to $\mathrm{O}_{3}$ had more pronounced lung inflammation and higher mortality rates compared to males [29]. Our additional work demonstrated that gonadal hormones are responsible for the observed sex differences, indicating that both sex and air pollution may alter the effectiveness of lung host defense [28]. Recently, we have showed sex differences in the messenger RNA (mRNA) expression of cytokines, chemokines, and oxidative stress-related enzymes in the lungs of filtered air (FA, control) and $\mathrm{O}_{3}$ exposed animals [39].

The cytokine IL-6 demonstrates pleiotropy and functional redundancy. We have previously demonstrated that neutrophil-attracting chemokines (Ccl20, $\mathrm{Cxcl} 5$, and
Cxcl2) and pro-inflammatory cytokine IL-6 mRNAs are most affected by ozone inhalation in both males and females, where females had significantly higher expression levels compared to the males [39]. It has also been reported that ozone increases airway neutrophil recruitment, which contributes to acute lung injury and hyper-reactivity and promotes inflammatory lung diseases [40-43]. The ability of alveolar macrophages to express IL- 6 after ozone exposure and importance of IL-6 in pulmonary neutrophil recruitment following ozone exposure raises an important question, whether IL-6 and its sequential downstream pathways exhibit any sex differences and whether those differences can be accounted for higher susceptibility and severity of lung diseases in females. In an effort to study the overall effects of $\mathrm{O}_{3}$ in mediating acute inflammation and oxidative stress in the lungs of males and females, the present study evaluates a possible role of JAK2/STAT3 and AKT1/NF- $\mathrm{kB}$ signaling in relation to IL-6 and IL-6R response and the effects of the female estrous cycle in $\mathrm{O}_{3}$-induced lung inflammation.

At the cellular level, an inflammatory event is primarily characterized by an initial influx of neutrophils, which is subsequently replaced by inflammatory monocytes and $\mathrm{T}$ cells. IL-6 has been shown to be a key player in both acute and chronic inflammation and can dictate the profile of leukocyte recruitment during the inflammatory response via selective regulation of inflammatory chemokines/ cytokines and apoptotic events. This paper extends our previous work and describes the possible role of IL-6R-associated signaling pathways in the inflammatory response to $\mathrm{O}_{3}$ in the male and female lung, as well as the contributions of the female estrous cycle to this regulation. Our results indicate a sex-based differential, and estrous cycle stage-dependent lung immune response to $\mathrm{O}_{3}$, and involvement of two converging JAK2/STAT3 and AKT1/ $\mathrm{NF}-\mathrm{kB}$ pathways in $\mathrm{O}_{3}$-associated lung inflammation. To our knowledge, this is the first study specifically addressing the impact of the female reproductive cycle in lung inflammatory pathways associated with $\mathrm{O}_{3}$ exposure.

\section{Methods}

\section{Animals}

Adult male and female mice ( 8 weeks of age) from the C57BL/6 background were purchased from JAX laboratories (Bar Harbor, ME) and housed and maintained in a 12/12 h light/dark cycle, with food and water available ad libitum. The Pennsylvania State University College of Medicine Institutional Animal Care and Use Committee approved all procedures.

\section{Assessment of estrous cycle stage in female mice}

Assessment of estrous cycle stages in females was performed by the analysis of vaginal secretions for at least three consecutive cycles, as described previously [44]. 
Briefly, mice were restrained, and their vaginas were flushed daily with PBS. For vaginal cytology, a smear of vaginal flush was prepared and observed unstained under light microscope at $\times 10$ and $\times 40$ objectives. Determination of the estrous cycle stage was decided on the proportion among three cell types: nucleated epithelial cells, leucocytes, and cornified cells, where (A) proestrus was defined for a smear containing predominantly nucleated epithelial cells; (B) estrus was defined for a smear with majority of anucleated cornified cells; (C) metestrus, for smears consisting of the three types of cells; and (D) diestrus, in smears consisting predominantly of leucocytes. Animals that did not cycle regularly were excluded from the experiment.

\section{Ozone exposure}

Male and female mice (at different stages of estrous cycle) were exposed to $2 \mathrm{ppm}$ of $\mathrm{O}_{3}$ or FA (control) for $3 \mathrm{~h}$, in different chambers as described previously [22, 45, 46]. Briefly, mice were exposed to ozone or to FA at the same time in separate chambers. Each chamber consisted of a 3.7-L closed glass vessel into which glass containers with wire mesh tops were placed. The temperature was maintained at $25{ }^{\circ} \mathrm{C}$, humidity was set to $50 \%$, and the flow rate was $15 \mathrm{~L} / \mathrm{min}$ through each (FA and ozone) chamber. Air flow and ozone content were continually monitored. All FA and ozone exposures were conducted in parallel. Animals were sacrificed $4 \mathrm{~h}$ after exposure, and total lung tissue was collected for Western blot experiments $(n=22$ animals per group). Blood was also collected in female mice for serum hormone determinations.

\section{Assessment of serum hormone levels in female mice}

Serum levels of progesterone were determined by ELISA (cat \#MBS266675, MyBioSource, San Diego, CA) at the Penn State Hershey core endocrine laboratory. Serum levels of luteinizing hormone (MBS041300, MyBioSource, San Diego, CA) were also determined by ELISA.

\section{Protein extraction and Western blot}

RIPA buffer (Thermo, Rockford, IL) was used to extract protein from pulverized lung tissues, following the manufacturer's protocol. Protein concentration was determined by BCA assay (Thermo, Rockford, IL), and $20 \mu \mathrm{g}$ were used for Western blot analysis with the respective antibodies. For densitometric quantitation of Western blots, images were digitized by using a BioRad GS800 calibrated densitometer and analyzed on BioRad Quantity One software (Penn State Hershey Core Facility). Quantification for the difference in the expression was assessed following normalization to GAPDH.

\section{Primary and secondary antibodies}

Antibodies to IL-6 (AB6672) and IL-6R (AB83053), STAT3-unphosphorylated (AB68153), STAT3 Serine 727 phosphorylation (AB86430), STAT3 Tyrosine 705 phosphorylation (AB76315), JAK2-unphosphorylated (AB98031 and AB108596), JAK2 phosphorylated-Y1007+Y1008 (AB68268), NF-kB-p105/p50 (AB32360), AKT1 (AB32505), and GAPDH (AB9485) were obtained from Abcam (Cambridge, MA). All HRP-conjugated secondary antibodies were from Invitrogen.

\section{Statistical analysis}

A total of 88 animals were used in the study with 22 animals in each study arm comprising of male filter air, male ozone, female filter air, and female ozone. Based on the assessment of estrous cycle stages, females $(n=44)$ were further sub-grouped in non-proestrus female filter air, non-proestrus female ozone, proestrus female filter air, and proestrus female ozone categories. The differences between $\mathrm{O}_{3}$ - and FA-exposed animals were first compared by Kruskal-Wallis analysis of variance of the densitometric data of Western blot experiments. The values are depicted as mean with SD. $p \leq 0.05$ were considered significant, where, $" p \leq 0.05, * * p \leq 0.01,{ }^{* * * *} p \leq 0.001$ and ${ }^{* * * *} p \leq 0.0001$ are the levels of statistical significance compared to controls. Statistical analyses were performed using GraphPad Prism version 6.00 for Mac OS X, GraphPad Software (La Jolla California USA, www.GraphPad.com). To further ascertain the effect of sex and female estrous cycle stages, a two-way ANOVA analysis was performed using SPSS version 22.0 (IBM Corp. Released 2013. IBM SPSS Statistics for Windows, Version 22.0. Armonk, NY: IBM Corp.) on IL6, IL6R, STAT3 (unphosphorylated), STAT3 Serine 727 and Tyrosine 705 phosphorylation, JAK2 and JAK2 (Y1007 +Y1008) phosphorylation, NF-kB (p105/p50), and AKT1 expression with filter air and ozone exposure. Residual analysis was performed to test for the assumptions of the twoway ANOVA. Outliers were assessed by inspection of a boxplot, normality was assessed using Shapiro-Wilk's normality test for each cell of the design, and homogeneity of variances was assessed by Levene's test. Analyses of simple main effects (the effect of one factor at each level of the other factor) for sex and estrous cycle stage compared to the type of exposure were performed with statistical significance receiving a Bonferroni adjustment and being accepted at the $p<0.025$ level. For the interpretation of significant interactions, it was also investigated if the interaction effects were ordinal or disordinal.

\section{Results}

Ozone-associated lung inflammation and up-regulation of IL-6 and IL-6R expression

With one-way analysis of variance, ozone exposure resulted in a significant increase in the expression levels of 
IL- 6 in both male and female mice compared to the matched controls exposed to FA (Fig. 1a, b, Additional file 1: Figure S1-a). However, the expression of IL-6 was significantly higher in females in comparison to males exposed to $\mathrm{O}_{3}$ (Fig. 1a, b). A two-way ANOVA on the sex and ozone/filter air exposure showed statistically significant interaction $F(1,52)=6.55, p=0.013$, partial $\eta 2=0.112$. An analysis of simple main effects for sex and exposure type with Bonferroni adjustment revealed statistically significant difference in IL6 expression score between filter air and ozone exposure. Ozone-exposed females had a significant increase in the IL6 score of 0.566 (95\% CI, 0.313 to 0.819 ) points compared to the ozone-exposed males, $F(1,52)=20.11, p=<0.0005$, partial $\eta 2=0.279$ (Table 1). Similarly, females with ozone exposure had significant increase in the IL6 score of 2.641 (95\% CI, 2.38 to 2.89) points compared to the females exposed to the filter air, $F(1,52)=438.0, p=<0.0005$, partial $\eta 2=0.894$ (Table 1). Interaction effect of sex and exposure for IL6 expression is given in Fig. 1c, d.

To evaluate the contributions of female hormones to this regulation, we further investigated IL-6 levels in females exposed to $\mathrm{O}_{3}$ or FA at different stages of the estrous cycle. Serum hormone measurements performed at the time of sample collection (between 6:00 pm and 7:00 pm) indicated higher levels of luteinizing hormone and progesterone in proestrus vs. other estrous cycle stages (Table 2), as previously described [47]. Thus, for the purpose of this work, we performed comparisons of lung protein expression levels in proestrus vs. the rest of the days combined. With one-way analysis of variance, we found that exposure to $\mathrm{O}_{3}$ on the day of proestrus had a slightly higher but non-significantly different effect on lung IL-6 expression than exposure in non-proestrus cycle stages (Fig. 1h, i); however statistically, the $\mathrm{O}_{3}$ exposed non-proestrus cycle stage had a significant increase in the expression due to much lower IL-6 levels in the matched FA-exposed group. A two-way ANOVA examining the effects of estrous cycle stages and filter air/ozone exposure on the IL6 expression, showed statistically significant interaction $F(1,24)=4.45, p=0.045$, partial $\eta 2=0.156$. An analysis of simple main effects for estrous cycle stages and exposure type with Bonferroni adjustment revealed statistically significant difference in IL6 expression score. Proestrus females exposed to ozone had a significant increase in the IL6 score of 2.462 (95\% CI, 1.97 to 2.95 ) points compared to the filtered air-exposed proestrus females, $F(1,24)=108.67$, $p=<0.0005$, partial $\eta 2=0.819$ (Table 1). Similarly, ozone-exposed proestrus females had a significant increase in the IL6 score of 1.245 (95 \% CI, 0.757 to 1.732) points compared to the non-proestrus females exposed to ozone, $F(1,24)=27.77, p=<0.0005$, partial $\eta 2=0.536$ (Table 1). Filter air/ozone exposure on each sex alone and estrous cycle type alone in relation to the IL6 is given in Table 1. Interaction effect of exposure and estrous cycle stages for IL6 expression is given in Fig. 1j, k.

Levels of IL-6R exerted an overall increase (Additional file 1: Figure S1-b) and a marked difference in expression between male and female mice exposed to $\mathrm{O}_{3}$ or FA (Fig. 1a, e). With one-way analysis of variance, the basal levels of IL-6R in female mice exposed to FA were lower compared to male mice. With $\mathrm{O}_{3}$ exposure, we found little to no change in the expression levels of IL-6R in male mice, while a very significant increase in female mice (Fig. 1a, e). A two-way ANOVA on the sex and ozone/filter air exposure showed statistically significant interaction $F(1,52)=37.94, p=<0.0005$, partial $\eta 2=0.422$. An analysis of simple main effects for sex and exposure type with Bonferroni adjustment revealed statistically significant difference in IL6R expression score between filter air and ozone exposure. Ozone-exposed females had a significant increase in the IL6R score of 1.409 (95\% CI, 0.984 to 1.835$)$ points compared to the ozone-exposed males, $F(1,52)=44.13, p=<0.0005$, partial $\eta 2=0.459$ (Table 3). Similarly, females with ozone exposure had a significant increase in the IL6R score of 1.785 (95\% CI, 1.36 to 2.211) points compared to the females exposed to the filter air, $F(1,52)=70.84$, $p=<0.0005$, partial $\eta 2=0.577$ (Table 3). Interaction effect of sex and exposure for IL6R expression is given in Fig. 1f, g.

In concordance with the IL-6 expression, one-way analysis of variance of female mice exposed to $\mathrm{O}_{3}$ at different estrous cycle stages showed a slightly higher, but not significant, expression of IL-6R in proestrus compared to non-proestrus (Fig. 1h, l). A two-way ANOVA examining the effects of estrous cycle stages and filter air/ ozone exposure on the IL6R expression, showed statistically insignificant interaction $F(1,24)=0.076, p=0.785$, partial $\eta 2=0.003$. However, an analysis of simple main effects for estrous cycle stages and exposure type with Bonferroni adjustment revealed statistically significant difference in IL6R expression score. Non-proestrus female exposed to ozone had a significant increase in the IL6R score of 2.592 (95\% CI, 2.104 to 2.954) points compared to the filtered air-exposed non-proestrus female, $F(1,24)=150.94, p=<0.0005$, partial $\eta 2=0.863$ (Table 3). Likewise, filtered air-exposed proestrus females had a significant increase in the IL6R score of 0.659 (95\% CI, 0.234 to 1.084 ) points compared to the nonproestrus females exposed to the filter air, $F(1,24)=$ 10.240, $p=0.004$, partial $\eta 2=0.299$ (Table 3). Filter air/ ozone exposure on each sex alone and estrous cycle type alone in relation to the IL6R is given in Table 3. Interaction effect of exposure and estrous cycle stages for IL6R expression is given in Fig. 1m, n. 
a

b
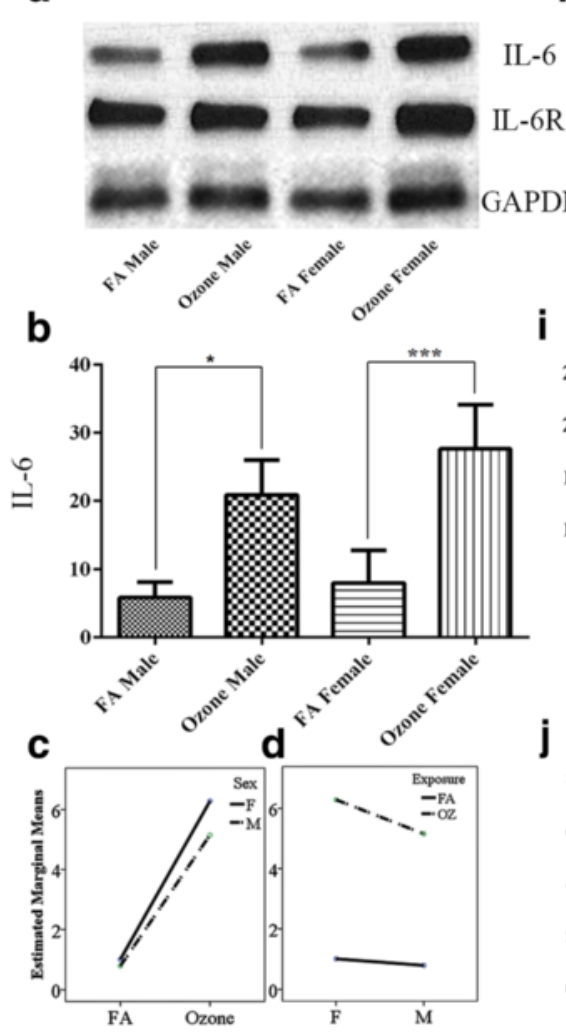

\section{e$$
\text { e }
$$ \\ e}
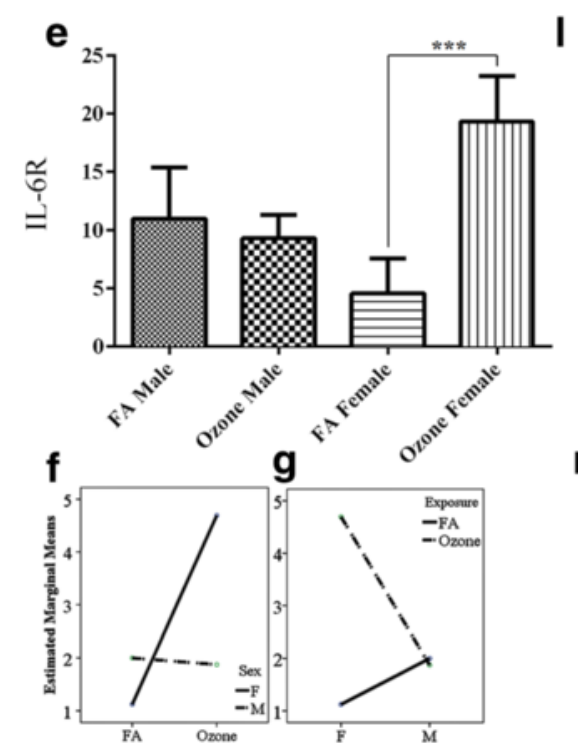

h

तs

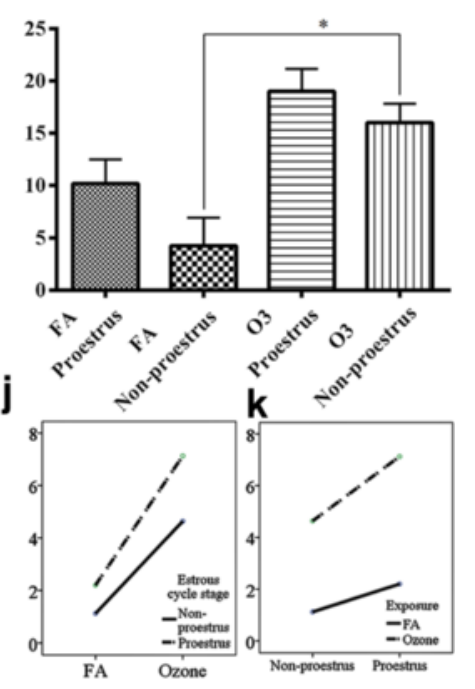

I
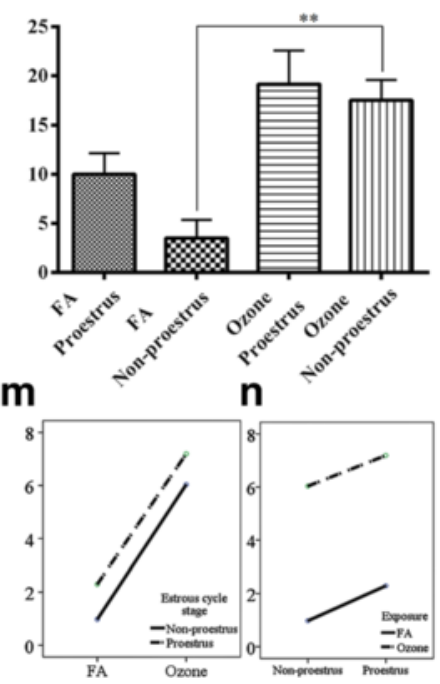

Fig. 1 IL6 and IL6R expression and effect of ozone exposure. Left panels: a Representative Western blot images of IL6 and IL6R expression in males and females with filter air and $\mathrm{O}_{3}$ exposure; univariate analysis of IL6 (b) and IL6R (e), expression in males and females, with FA and $\mathrm{O}_{3}$ exposure; two-way ANOVA interaction effect of sex (c) and exposure (d), for IL6 expression and sex (f) and exposure (g), for IL6R expression. Right panels: $\mathbf{h}$ Representative Western blot images of IL6 and IL6R expression in estrous cycle stages of females, with filter air and $\mathrm{O}_{3}$ exposure; univariate analysis of IL6 (i) and IL6R (I), expression in estrous cycle stages of females, with FA and $\mathrm{O}_{3}$ exposure. Two-way ANOVA interaction effect of

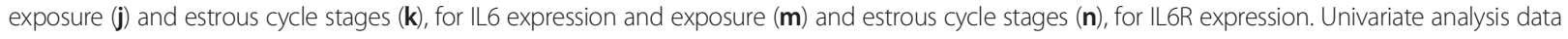
expressed as Ranks-Kruskal-Wallis test of densitometric analysis; the values are depicted as mean with SD, where ${ }^{*} p \leq 0.05$, ${ }^{* *} p \leq 0.01$, and ${ }^{* * *} p \leq 0.001$ are the levels of statistical significance compared to controls ( $n=6-8$ per group). Two-way ANOVA for IL6 and IL6R analysis is given in Tables 1 and 3, respectively 
Table 1 Two-way ANOVA for univariate and pairwise comparisons between gender, estrous cycle stages, and exposure for IL6 expression

\begin{tabular}{|c|c|c|c|c|c|c|c|}
\hline \multicolumn{8}{|c|}{ Univariate tests: dependent variable: IL6 } \\
\hline & & & $d f$ & $F$ & Sig. & \multicolumn{2}{|l|}{ Partial 2} \\
\hline \multirow[t]{4}{*}{ Analysis of gender and exposure } & \multirow[t]{2}{*}{ Exposure } & FA & 1,52 & 0.751 & 0.390 & \multicolumn{2}{|l|}{0.014} \\
\hline & & Ozone & 1,52 & 20.113 & $<0.0005$ & \multicolumn{2}{|l|}{0.279} \\
\hline & \multirow[t]{2}{*}{ Sex } & $\mathrm{F}$ & 1,52 & 438.088 & $<0.0005$ & \multicolumn{2}{|l|}{0.894} \\
\hline & & M & 1,52 & 299.716 & $<0.0005$ & \multicolumn{2}{|l|}{0.852} \\
\hline \multirow{4}{*}{$\begin{array}{l}\text { Analysis of female estrous cycle } \\
\text { stages and exposure }\end{array}$} & \multirow[t]{2}{*}{ Estrous cycle stage } & Non-proestrus & 1,24 & 55.368 & $<0.0005$ & \multicolumn{2}{|l|}{0.698} \\
\hline & & Proestrus & 1,24 & 108.679 & $<0.0005$ & \multicolumn{2}{|l|}{0.819} \\
\hline & \multirow[t]{2}{*}{ Exposure } & FA & 1,24 & 5.228 & 0.031 & \multicolumn{2}{|l|}{0.179} \\
\hline & & Ozone & 1,24 & 27.777 & $<0.0005$ & \multicolumn{2}{|l|}{0.536} \\
\hline \multicolumn{8}{|c|}{ Pairwise comparisons: dependent variable: IL6 } \\
\hline & & & (I) Sex & (J) Sex & Mean difference & \multicolumn{2}{|c|}{$95 \%$ Cl for difference } \\
\hline & & & & & & \multicolumn{2}{|c|}{ Lower bound Upper bound } \\
\hline \multirow[t]{4}{*}{ Analysis of gender and exposure } & \multirow[t]{2}{*}{ Exposure } & FA & $\mathrm{F}$ & M & 0.109 & 0.144 & 0.363 \\
\hline & & Ozone & $\mathrm{F}$ & M & 0.566 & 0.313 & 0.819 \\
\hline & \multirow[t]{2}{*}{ Sex } & $\mathrm{F}$ & Ozone & FA & 2.641 & 2.388 & 2.895 \\
\hline & & M & Ozone & FA & 2.185 & 1.932 & 2.438 \\
\hline \multirow{4}{*}{$\begin{array}{l}\text { Analysis of female estrous cycle } \\
\text { stages and exposure }\end{array}$} & \multirow[t]{2}{*}{ Estrous cycle stage } & Non-proestrus & Ozone & FA & 1.758 & 1.270 & 2.245 \\
\hline & & Proestrus & Ozone & FA & 2.462 & 1.975 & 2.950 \\
\hline & \multirow[t]{2}{*}{ Exposure } & FA & Proestrus & Non-proestrus & .540 & 0.053 & 1.028 \\
\hline & & Ozone & Proestrus & Non-proestrus & 1.245 & 0.757 & 1.732 \\
\hline
\end{tabular}

\section{Ozone-associated lung inflammation and expression of STAT3 unphosphorylated and STAT3 Serine 727 and Tyrosine 705 phosphorylation}

In order to establish the possible role of STAT3 in relation to the IL-6 and IL-6R expression, we further investigated the expression levels of STAT3 unphosphorylated, as well as STAT3 Serine 727 (p-S727) and Tyrosine 705 (p-Y705) phosphorylation in mice exposed to $\mathrm{O}_{3}$ or FA. The expression levels were further compared between males and females, and the impact of exposure in different female estrous cycle stages was assessed.

One-way analysis of variance revealed no difference in the levels of lung unphosphorylated STAT3 with $\mathrm{O}_{3}$ or FA exposure (Additional file 1: Figure S1-c). Similarly, no sex differences were observed in either groups (Fig. 2a, b). Similarly, a two-way ANOVA on the sex and ozone/filter air exposure showed statistically insignificant interaction $F(1,52)=1.765, p=0.190$, partial $\eta 2=0.033$. However, analysis of simple main effects for sex and exposure type with Bonferroni adjustment revealed statistically significant but marginal difference in unphosphorylated
STAT3 expression score between filter air and ozone exposure. Ozone-exposed females had a very marginal but significant increase in the STAT3 score of 0.135 (95\% CI, 0.003 to 0.267$)$ points compared to the ozone-exposed males, $F(1,52)=4.22, p=0.045$, partial $\eta 2=0.075$ (Table 4), whereas males with filter air exposure had an insignificant increase in the STAT3 score of 0.098 (95\% CI, 0.034 to 0.230 ) points compared to the males exposed to the ozone, $F(1,52)=2.217, p=0.143$, partial $\eta 2=0.041$ (Table 4). Interaction effect of sex and exposure for unphosphorylated STAT3 expression is given in Fig. 2c, d.

However, one-way analysis of variance of different female estrous cycle stages exerted a significant difference. We found that STAT3 unphosphorylated levels were significantly decreased in females exposed to $\mathrm{O}_{3}$ in non-proestrus cycle stages, whereas females exposed in proestrus showed a marked increase with $\mathrm{O}_{3}$ exposure compared to the matched control females (Fig. $2 \mathrm{k}, \mathrm{l}$ ). A two-way ANOVA examining the effects of estrous cycle stages and filter air/ozone exposure on the unphosphorylated STAT3 expression showed statistically insignificant

Table 2 Serum hormone levels in female mice

\begin{tabular}{lcccc}
\hline & Proestrus & Estrus & Metestrus & Diestrus \\
\hline $\mathrm{LH}(\mathrm{m} / \mathrm{U} / \mathrm{ml})$ & $11.0 \pm 0.9$ & $3.4 \pm 0.4$ & $4.4 \pm 0.5$ & $3.8 \pm 0.5$ \\
Progesterone $(\mathrm{ng} / \mathrm{ml})$ & $5.6 \pm 1.3$ & $2.3 \pm 0.4$ & $2.1 \pm 0.3$ & $2.0 \pm 0.2$ \\
\hline
\end{tabular}

${ }^{*} p<0.05$ vs. proestrus 
Table 3 Two-way ANOVA for univariate and pairwise comparisons between gender, estrous cycle stages, and exposure for IL6R expression

\begin{tabular}{|c|c|c|c|c|c|c|c|}
\hline \multicolumn{8}{|c|}{ Univariate tests: dependent variable: IL6R } \\
\hline & & & $d f$ & $F$ & Sig. & \multicolumn{2}{|l|}{ Partial 2} \\
\hline \multirow[t]{4}{*}{ Analysis of gender and exposure } & \multirow[t]{2}{*}{ Exposure } & FA & 1,52 & 4.275 & 0.044 & \multicolumn{2}{|l|}{0.076} \\
\hline & & Ozone & 1,52 & 44.137 & $<0.0005$ & \multicolumn{2}{|l|}{0.459} \\
\hline & \multirow[t]{2}{*}{ Sex } & $\mathrm{F}$ & 1,52 & 70.840 & $<0.0005$ & \multicolumn{2}{|l|}{0.577} \\
\hline & & M & 1,52 & 0.087 & 0.770 & \multicolumn{2}{|l|}{0.002} \\
\hline \multirow{4}{*}{$\begin{array}{l}\text { Analysis of female estrous cycle } \\
\text { stages and exposure }\end{array}$} & \multirow[t]{2}{*}{ Estrous cycle stage } & Non-proestrus & 1,24 & 150.946 & $<0.0005$ & \multicolumn{2}{|l|}{0.863} \\
\hline & & Proestrus & 1,24 & 141.524 & $<0.0005$ & \multicolumn{2}{|l|}{0.855} \\
\hline & \multirow[t]{2}{*}{ Exposure } & FA & 1,24 & 10.240 & 0.004 & \multicolumn{2}{|l|}{0.299} \\
\hline & & Ozone & 1,24 & 7.898 & 0.010 & \multicolumn{2}{|l|}{0.248} \\
\hline \multicolumn{8}{|c|}{ Pairwise comparisons: dependent variable: IL6R } \\
\hline & & & (I) Sex & (J) Sex & Mean difference & \multicolumn{2}{|c|}{$95 \%$ Cl for difference } \\
\hline & & & & & & \multicolumn{2}{|c|}{ Lower bound Upper bound } \\
\hline \multirow[t]{4}{*}{ Analysis of gender and exposure } & \multirow[t]{2}{*}{ Exposure } & FA & M & $\mathrm{F}$ & 0.439 & 0.013 & 0.864 \\
\hline & & Ozone & $\mathrm{F}$ & M & 1.409 & 0.984 & 1.835 \\
\hline & \multirow[t]{2}{*}{ Sex } & $\mathrm{F}$ & Ozone & FA & 1.785 & 1.360 & 2.211 \\
\hline & & M & FA & Ozone & 0.062 & 0.363 & 0.488 \\
\hline \multirow{4}{*}{$\begin{array}{l}\text { Analysis of female estrous cycle } \\
\text { stages and exposure }\end{array}$} & \multirow[t]{2}{*}{ Estrous cycle stage } & Non-proestrus & Ozone & FA & 2.529 & 2.104 & 2.954 \\
\hline & & Proestrus & Ozone & FA & 2.449 & 2.024 & 2.874 \\
\hline & \multirow[t]{2}{*}{ Exposure } & FA & Proestrus & Non-proestrus & 0.659 & 0.234 & 1.084 \\
\hline & & Ozone & Proestrus & Non-proestrus & 0.579 & 0.154 & 1.003 \\
\hline
\end{tabular}

interaction $F(1,24)=14.57, p=0.001$, partial $\eta 2=0.378$. Analysis of simple main effects for estrous cycle stages and exposure type with Bonferroni adjustment revealed statistically significant difference in unphosphorylated STAT3 expression score. Proestrus females exposed to ozone had a significant increase in the STAT3 score of 0.414 (95\% CI, 0.201 to 0.628 ) points compared to the filtered air-exposed proestrus females, $F(1,24)=16.113$, $p=0.001$, partial $\eta 2=0.402$ (Table 4). Likewise, ozoneexposed proestrus females had a significant increase in the STAT3 score of 0.588 (95\% CI, 0.375 to 0.801 ) points compared to the non-proestrus females exposed to ozone, $F(1,24)=32.414, p=<0.0005$, partial $\eta 2=0.575$ (Table 4). Filter air/ozone exposure on each sex alone and estrous cycle type alone in relation to the unphosphorylated STAT3 is given in Table 4. Interaction effect of exposure and estrous cycle stages for unphosphorylated STAT3 expression is given in Fig. $2 \mathrm{~m}$, $\mathrm{n}$.

When we compared he levels of STAT3 S727 phosphorylation in these mice, we found an overall increase with $\mathrm{O}_{3}$ exposure (Additional file 1: Figure S1-d). These were comparable in males exposed to $\mathrm{O}_{3}$ or FA and in females exposed to FA. However, females exposed to $\mathrm{O}_{3}$ displayed a slight but not significant increase in the STAT3 p-S727 levels vs. females exposed to FA (Fig. 2a, e). Two-way ANOVA on the sex and ozone/filter air exposure showed statistically significant interaction $F$
$(1,60)=13.568, p=<0.0005$, partial $\eta 2=0.184$. Analysis of simple main effects for sex and exposure type with Bonferroni adjustment revealed statistically significant difference in STAT3 S727 phosphorylation expression score between filter air and ozone exposure. Ozoneexposed females had a significant increase in the STAT3 serine 727 score of 1.009 (95\% CI, 0.622 to 1.397) points compared to the ozone-exposed males, $F(1,60)=27.137$, $p=<0.0005$, partial $\eta 2=0.311$ (Table 5). Similarly, females with ozone exposure had significant increase in the STAT3 serine 727 score of 0.804 (95 \% CI, 0.416 to 1.191 ) points compared to the females exposed to the filter air, $F(1,60)=17.209, p=<0.0005$, partial $\eta 2=0.223$ (Table 5). Interaction effect of sex and exposure for STAT3 p-S727 expression is given in Fig. 2f, g.

With one-way analysis of variance, females exposed to $\mathrm{O}_{3}$ in proestrus depicted a markedly higher, but not significant, phosphorylation compared to the females exposed in non-proestrus (Fig. 2k, o). Two-way ANOVA examining the effects of estrous cycle stages and filter air/ ozone exposure on the STAT3 serine 727 expression showed statistically significant interaction $F(1,28)=$ $38.710, p=<0.0005$, partial $\eta 2=0.580$. Simple main effects for estrous cycle stages and exposure type with Bonferroni adjustment revealed statistically significant difference in STAT3 serine 727 expression score. Proestrus females exposed to ozone had a significant increase in the STAT3 


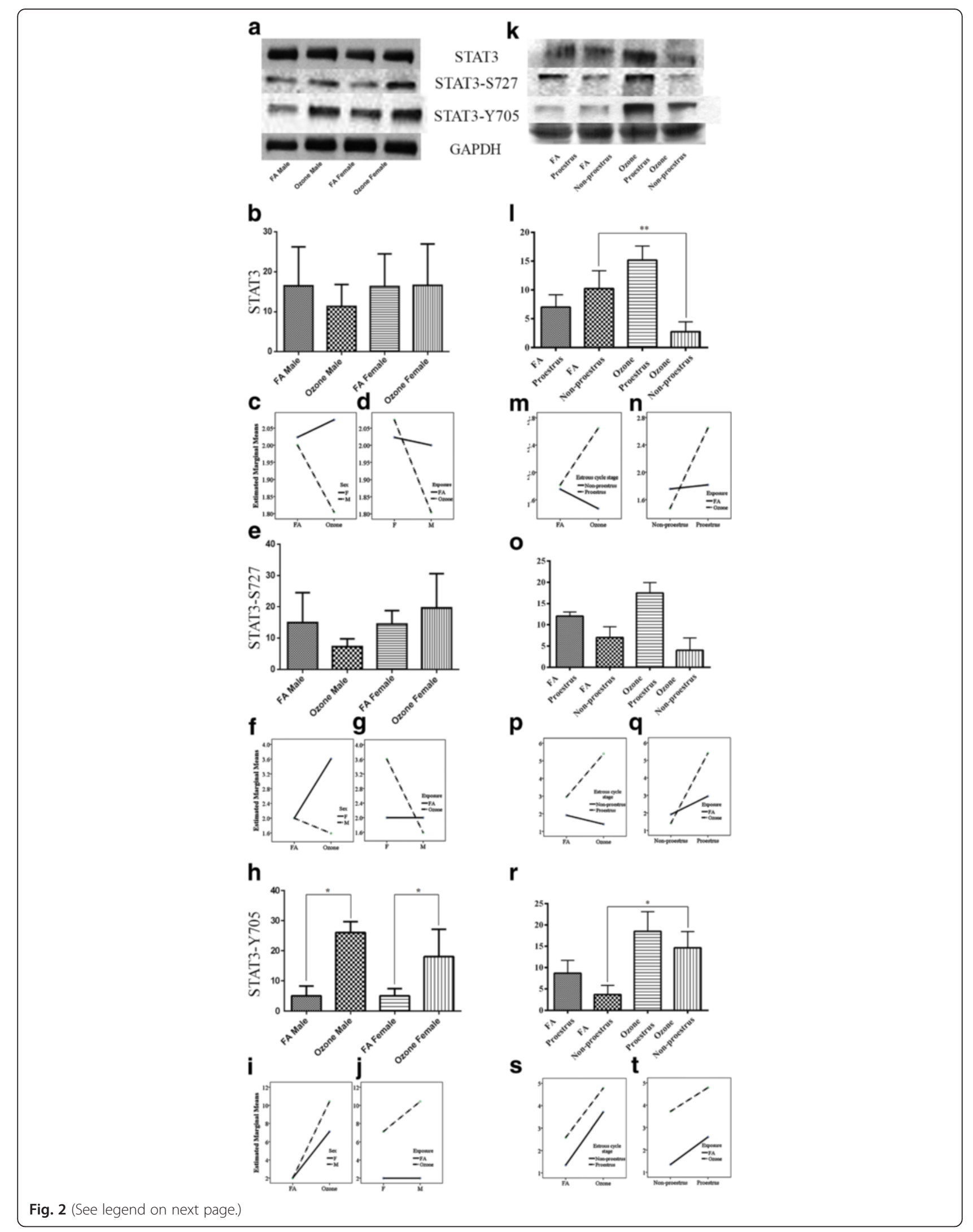


(See figure on previous page.)

Fig. 2 STAT3, STAT3 Serine 727, and STAT3 Tyrosine 705 phosphorylation and effect of ozone exposure. Left panels: a Representative Western blot images of STAT3, STAT3 Serine 727 and STAT3 Tyrosine 705 phosphorylation expression in males and females with filter air and $\mathrm{O}_{3}$ exposure; univariate analysis of STAT3 (b), STAT3 Serine 727 (e), and STAT3 Tyrosine 705 (h), expression in males and females, with FA and $\mathrm{O}_{3}$ exposure; Two-way ANOVA interaction effect of sex (c) and exposure (d), for STAT3 expression, sex $(\mathbf{f})$ and exposure $(\mathbf{g})$, for STAT3 Serine 727 expression and sex (i) and exposure (j), for STAT3 Tyrosine 705 expression. Right panels: $\mathbf{k}$ Representative Western blot images of STAT3, STAT3 Serine 727, and STAT3 Tyrosine 705 phosphorylation expression in estrous cycle stages of females, with filter air and $\mathrm{O}_{3}$ exposure; univariate analysis of STAT3 (I), STAT3 Serine 727 (o), and STAT3 Tyrosine 705 (r), expression in estrous cycle stages of females, with FA and $\mathrm{O}_{3}$ exposure. Two-way ANOVA interaction effect of exposure $(\mathbf{m})$ and estrous cycle stages $(\mathbf{n})$, for STAT3 expression, exposure $(\mathbf{p})$ and estrous cycle stages $(\mathbf{q})$, for STAT3 Serine 727 expression, and exposure (s) and estrous cycle stages (t), for STAT3 Tyrosine 705 expression. Univariate analysis data expressed as Ranks-KruskalWallis test of densitometric analysis; the values are depicted as mean with $\mathrm{SD}$, where ${ }^{*} p \leq 0.05$ and ${ }^{* *} p \leq 0.01$ are the levels of statistical significance compared to controls ( $n=6-8$ per group). Two-way ANOVA for STAT3, STAT3 Serine 727, and STAT3 Tyrosine 705 phosphorylation expression analysis is given in Tables 4, 5, and 6, respectively

serine 727 score of 1.223 (95\% CI, 0.880 to 1.567 ) points compared to the filtered air-exposed proestrus females, $F \quad(1,28)=53.117, \quad p=<0.0005$, partial $\eta 2=0.655$ (Table 5). Similarly, ozone-exposed proestrus females had a significant increase in the STAT3 serine 727 score of 1.995 (95\% CI, 1.652 to 2.339) points compared to the non-proestrus females exposed to ozone, $F(1,28)=$ 141.295, $p=<0.0005$, partial $\eta 2=0.835$ (Table 5). Filter air/ ozone exposure on each sex alone and estrous cycle type alone in relation to the unphosphorylated STAT3 serine 727 phosphorylation is given in Table 5. Interaction effect of exposure and estrous cycle stages for SATAT3 p-S727 expression is given in Fig. 2p, q.
Univariate analysis of lung STAT3 Y705 phosphorylation revealed a significant overall increase in animals exposed to $\mathrm{O}_{3}$ compared to FA (Additional file 1: Figure S1-e) irrespective of sex differences (Fig. 2a, h). Two-way ANOVA on the sex and ozone/filter air exposure also showed statistically significant interaction $F(1,52)=12.40$, $p=0.001$, partial $\eta 2=0.193$. Analysis of simple main effects for sex and exposure type with Bonferroni adjustment revealed statistically significant difference in STAT3 tyrosine 705 phosphorylation expression score between filter air and ozone exposure. Ozone-exposed male had significant increase in the STAT3 tyrosine 705 score of 1.645 (95\% CI, 0.982 to 2.308) points compared to the ozone-exposed

Table 4 Two-way ANOVA for univariate and pairwise comparisons between gender, estrous cycle stages, and exposure for STAT3 expression

\begin{tabular}{|c|c|c|c|c|c|c|c|}
\hline \multicolumn{8}{|c|}{ Univariate tests: dependent variable: STAT3 } \\
\hline & & & $d f$ & F & Sig. & \multicolumn{2}{|l|}{ Partial 2} \\
\hline \multirow[t]{4}{*}{ Analysis of gender and exposure } & \multirow[t]{2}{*}{ Exposure } & FA & 1,52 & 0.031 & 0.862 & \multicolumn{2}{|l|}{0.001} \\
\hline & & Ozone & 1,52 & 4.220 & 0.045 & \multicolumn{2}{|l|}{0.075} \\
\hline & \multirow[t]{2}{*}{ Sex } & $\mathrm{F}$ & 1,52 & 0.152 & 0.698 & \multicolumn{2}{|l|}{0.003} \\
\hline & & M & 1,52 & 2.217 & 0.143 & \multicolumn{2}{|l|}{0.041} \\
\hline \multirow{4}{*}{$\begin{array}{l}\text { Analysis of female estrous cycle } \\
\text { stages and exposure }\end{array}$} & \multirow[t]{2}{*}{ Estrous cycle stage } & Non-proestrus & 1,24 & 1.916 & 0.179 & \multicolumn{2}{|l|}{0.074} \\
\hline & & Proestrus & 1,24 & 16.113 & 0.001 & \multicolumn{2}{|l|}{0.402} \\
\hline & \multirow[t]{2}{*}{ Exposure } & FA & 1,24 & 0.087 & 0.770 & \multicolumn{2}{|l|}{0.004} \\
\hline & & Ozone & 1,24 & 32.414 & $<.0005$ & \multicolumn{2}{|l|}{0.575} \\
\hline \multicolumn{8}{|c|}{ Pairwise comparisons: dependent variable: STAT3 } \\
\hline & & & (I) Sex & (J) Sex & Mean difference $(\mid-J)$ & \multicolumn{2}{|c|}{$95 \% \mathrm{Cl}$ for difference } \\
\hline & & & & & & Lower bound & Upper bound \\
\hline \multirow[t]{4}{*}{ Analysis of gender and exposure } & \multirow[t]{2}{*}{ Exposure } & FA & $\mathrm{F}$ & M & 0.012 & 0.120 & 0.143 \\
\hline & & Ozone & $\mathrm{F}$ & M & 0.135 & 0.003 & 0.267 \\
\hline & \multirow[t]{2}{*}{ Sex } & $\mathrm{F}$ & Ozone & FA & 0.026 & 0.106 & 0.157 \\
\hline & & M & FA & Ozone & 0.098 & 0.034 & 0.230 \\
\hline \multirow{4}{*}{$\begin{array}{l}\text { Analysis of female estrous cycle } \\
\text { stages and exposure }\end{array}$} & \multirow[t]{2}{*}{ Estrous cycle stage } & Non-proestrus & FA & Ozone & 0.143 & 0.070 & 0.356 \\
\hline & & Proestrus & Ozone & FA & 0.414 & 0.201 & 0.628 \\
\hline & \multirow[t]{2}{*}{ Exposure } & FA & Proestrus & Non-proestrus & 0.030 & 0.183 & 0.244 \\
\hline & & Ozone & Proestrus & Non-proestrus & 0.588 & 0.375 & 0.801 \\
\hline
\end{tabular}


Table 5 Two-way ANOVA for univariate and pairwise comparisons between gender, estrous cycle stages, and exposure for STAT3 Serine 727 phosphorylation expression

\begin{tabular}{|c|c|c|c|c|c|c|c|}
\hline \multicolumn{8}{|c|}{ Univariate tests: dependent variable: STAT3 Serine 727} \\
\hline & & & $d f$ & F & Sig. & \multicolumn{2}{|l|}{ Partial 2} \\
\hline \multirow[t]{4}{*}{ Analysis of gender and exposure } & \multirow[t]{2}{*}{ Exposure } & FA & 1,60 & 0.001 & 1.000 & \multicolumn{2}{|l|}{0.002} \\
\hline & & Ozone & 1,60 & 27.137 & $<0.0005$ & \multicolumn{2}{|l|}{0.311} \\
\hline & \multirow[t]{2}{*}{ Sex } & $\mathrm{F}$ & 1,60 & 17.209 & $<0.0005$ & \multicolumn{2}{|l|}{0.223} \\
\hline & & M & 1,60 & 1.126 & 0.293 & \multicolumn{2}{|l|}{0.018} \\
\hline \multirow{4}{*}{$\begin{array}{l}\text { Analysis of female estrous cycle } \\
\text { stages and exposure }\end{array}$} & \multirow[t]{2}{*}{ Estrous cycle stage } & Non-proestrus & 1,28 & 2.282 & 0.142 & \multicolumn{2}{|l|}{0.075} \\
\hline & & Proestrus & 1,28 & 53.117 & $<0.0005$ & \multicolumn{2}{|l|}{0.655} \\
\hline & \multirow[t]{2}{*}{ Exposure } & FA & 1,28 & 9.535 & 0.005 & \multicolumn{2}{|l|}{0.254} \\
\hline & & Ozone & 1,28 & 141.295 & $<.0005$ & \multicolumn{2}{|l|}{0.835} \\
\hline \multicolumn{8}{|c|}{ Pairwise comparisons: dependent variable: STAT3 Serine 727} \\
\hline & & & (l) Sex & (J) Sex & Mean difference $(\mid-J)$ & \multicolumn{2}{|c|}{$95 \%$ Cl for difference } \\
\hline & & & & & & Lower bound & Upper bound \\
\hline \multirow[t]{4}{*}{ Analysis of gender and exposure } & \multirow[t]{2}{*}{ Exposure } & FA & $\mathrm{F}$ & M & $2.500 \mathrm{E}-8$ & 0.388 & 0.388 \\
\hline & & Ozone & $\mathrm{F}$ & M & 1.009 & 0.622 & 1.397 \\
\hline & \multirow[t]{2}{*}{ Sex } & $\mathrm{F}$ & Ozone & FA & 0.804 & 0.416 & 1.191 \\
\hline & & M & FA & Ozone & 0.206 & 0.182 & 0.593 \\
\hline \multirow{4}{*}{$\begin{array}{l}\text { Analysis of female estrous cycle } \\
\text { stages and exposure }\end{array}$} & \multirow[t]{2}{*}{ Estrous cycle stage } & Non-proestrus & FA & Ozone & 0.254 & 0.090 & 0.597 \\
\hline & & Proestrus & Ozone & FA & 1.223 & 0.880 & 1.567 \\
\hline & \multirow[t]{2}{*}{ Exposure } & FA & Proestrus & Non-proestrus & 0.518 & 0.174 & 0.862 \\
\hline & & Ozone & Proestrus & Non-proestrus & 1.995 & 1.652 & 2.339 \\
\hline
\end{tabular}

females, $F(1,52)=24.80, p=<0.0005$, partial $\eta 2=0.323$ (Table 6) whereas males with ozone exposure had insignificant increase in the STAT3 tyrosine 705 score of 4.214 (95\% CI, 3.35 to 4.87 ) points compared to the males exposed to the filter air, $F(1,52)=162.686, p=<0.0005$, partial $\eta 2=0.758$ (Table 6). Interaction effect of sex and exposure for STAT3 p-Y705 expression is given in Fig. 2i, j.

Ozone exposure in females in proestrus exerted a slightly higher expression change in the STAT3 p-Y705 compared to females exposed in non-proestrus stages, but unilabiate analysis exhibited no significant differences between these groups (Fig. 2k, r). Similarly, two-way ANOVA examining the effects of estrous cycle stages and filter air/ozone exposure on the STAT3 tyrosine 705 expression showed statistically insignificant interaction $F(1,28)=0.143, p=0.709$, partial $\eta 2=0.005$. However, simple main effects for estrous cycle stages and exposure type with Bonferroni adjustment revealed statistically significant difference in STAT3 tyrosine 705 expression score. Non-proestrus female exposed to ozone had significant increase in the STAT3 tyrosine 705 score of 1.185 (95\% CI, 0.866 to 1.504 ) points compared to the filtered air-exposed non-proestrus female, $F(1,28)=58.045, p=<0.0005$, partial $\eta 2=0.675$ (Table 6) whereas filtered air-exposed proestrus females had significant increase in the STAT3 tyrosine 705 score of 0.617 (95\% CI, 0.299 to 0.936 ) points compared to the non-proestrus females exposed to the filter air, $F$ $(1,28)=15.759, p=<0.0005$, partial $\eta 2=0.360$ (Table 6). Filter air/ozone exposure on each sex alone and estrous cycle type alone in relation to the unphosphorylated STAT3 tyrosine 705 phosphorylation is given in Table 6 . Interaction effect of exposure and estrous cycle stages for STAT3 p-Y705 expression is given in Fig. 2s, t.

\section{Ozone-associated lung inflammation and expression of JAK2 and JAK2 phosphorylation}

Interleukin-6 preferentially activates STAT3 with phosphorylation of Y705 via the JAK signaling pathway. To assess activation of this mechanism in our model, we measured the levels of JAK2 and JAK2 phosphorylation (Y1007+Y1008) with relation to $\mathrm{O}_{3}$ and FA exposure and further comparison of sex differences and female estrous cycle.

Irrespective of sex differences, one-way analysis of variance of pooled data showed a significant increase in the expression of JAK2 unphosphorylated with $\mathrm{O}_{3}$ exposure compared to animals exposed to FA (Additional file 1: Figure S1-f). However, comparison of males and females represented deviations in the expression patterns, where $\mathrm{O}_{3}$ exposure resulted in an overall decrease in JAK2 expression in males, while females had a significant increase in JAK2 expression (Fig. 3a, b). Two-way ANOVA 
Table 6 Two-way ANOVA for univariate and pairwise comparisons between gender, estrous cycle stages, and exposure for STAT3 Tyrosine 705 phosphorylation expression

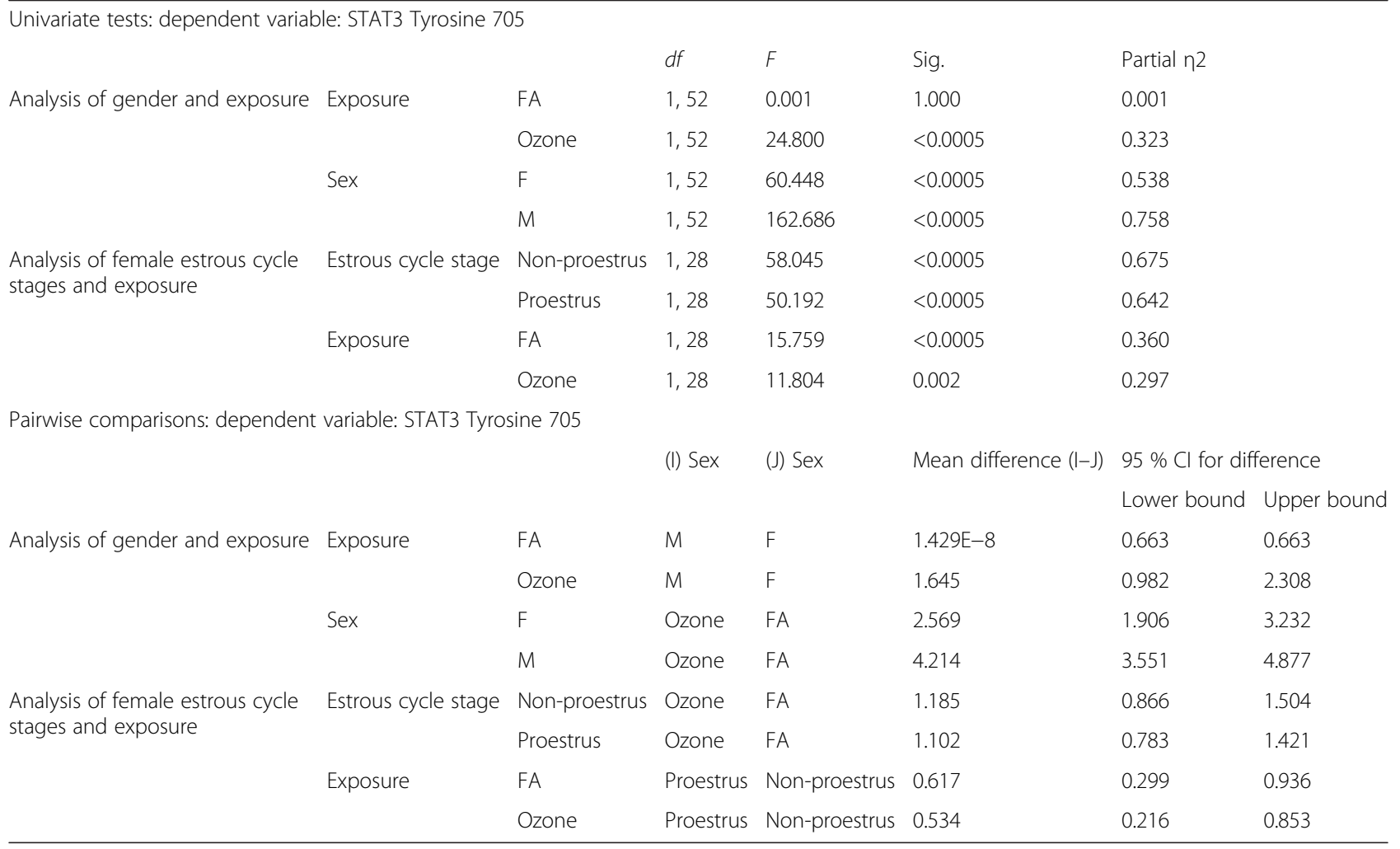

on the sex and ozone/filter air exposure showed statistically significant interaction $F(1,52)=627.9, p=<0.0005$, partial $\eta 2=0.924$. Analysis of simple main effects for sex and exposure type with Bonferroni adjustment revealed statistically significant difference in unphosphorylated JAK2 expression score between filter air and ozone exposure. Ozone-exposed female had significant increase in the unphosphorylated JAK2 expression score of 2.395 (95\% CI, 2.225 to 2.543 ) points compared to the ozone-exposed males, $F(1,52)=1190.013, p=<0.0005$, partial $\eta 2=0.958$ (Table 7) whereas females with ozone exposure had significant increase in the unphosphorylated JAK2 score of 2.165 (95\% CI, 2.026 to 2.304) points compared to the females exposed to the filter air, $F(1,52)=972.74$, $p=<0.0005$, partial $\eta 2=0.942$ (Table 7). Interaction effect of sex and exposure for JAK2 expression is given in Fig. 3c, d.

Univariate analysis of females at different estrous cycle stages revealed a higher and significant increase in the levels of unphosphorylated JAK2 in females exposed to $\mathrm{O}_{3}$ in proestrus compared to females exposed in nonproestrus stages and females exposed to FA (Fig. 3h, i). Two-way ANOVA examining the effects of estrous cycle stages and filter air/ozone exposure showed statistically significant interaction $F(1,36)=19.596, p=<0.0005$, partial $\eta 2=0.352$. Simple main effects for estrous cycle stages and exposure type with Bonferroni adjustment revealed statistically significant difference in unphosphorylated JAK2 expression score. Ozone-exposed non-proestrus females had significant increase in the unphosphorylated JAK2 score of 1.795 (95 \% CI, 1.603 to 1.987) points compared to the non-proestrus females exposed to the filter air, $F(1,36)=360.191, p=<0.0005$, partial $\eta 2=0.909$ (Table 7). Similarly, proestrus female exposed to ozone had significant increase in the unphosphorylated JAK2 score of 0.555 (95 \% CI, 0.363 to 0.747 ) points compared to the ozone-exposed non-proestrus female, $F(1,36)=34.392, p=<0.0005$, partial $\eta 2=0.489$ (Table 7). Filter air/ozone exposure on each sex alone and estrous cycle type alone in relation to the unphosphorylated JAK2 is given in Table 7. Interaction effect of exposure and estrous cycle stages for JAK2 expression is given in Fig. 3j, k.

JAK2 phosphorylation (Y1007+Y1008) showed an overall significant increase with $\mathrm{O}_{3}$ exposure compared to FA (Additional file 1: Figure S1g). Females showed a higher and significant expression of phosphorylated JAK2 (Y1007+Y1008) compared to $\mathrm{O}_{3}$-exposed males (Fig. 3a, e). Two-way ANOVA on the sex and ozone/filter air exposure showed statistically significant interaction $F(1,52)=23.991, p=<0.0005$, partial $\eta 2=0.316$. Analysis of simple main effects for sex and exposure type 


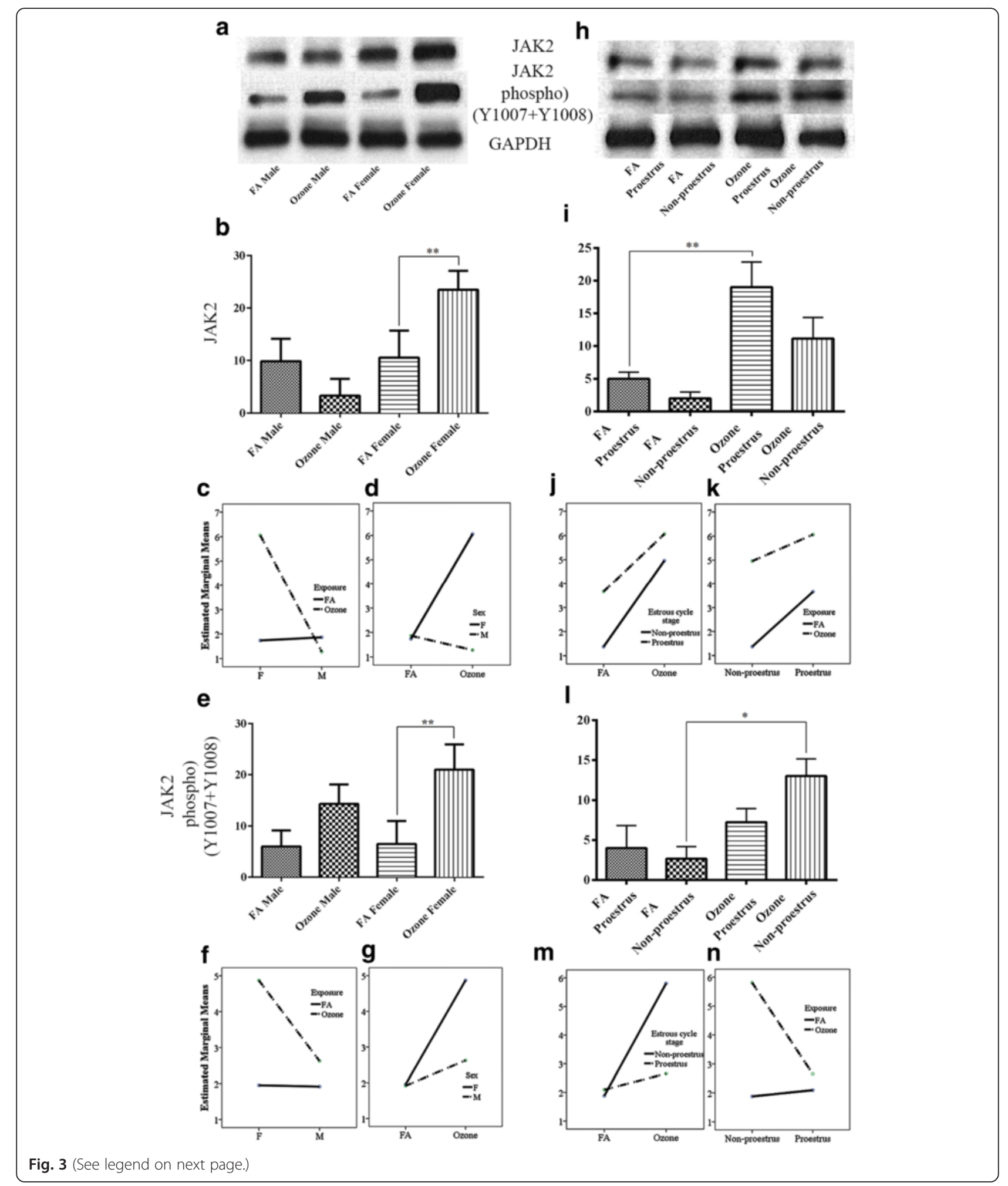


(See figure on previous page.)

Fig. 3 JAK2 and JAK2 phosphorylated (Y1007+Y1008) expression and effect of ozone exposure. Left panels: a Representative Western blot images of JAK2 and JAK2 phosphorylated (Y1007+Y1008) expression in males and females with filter air and $\mathrm{O}_{3}$ exposure; univariate analysis of JAK2 (b) and JAK2 (e) phosphorylated (Y1007+Y1008), expression in males and females, with FA and $\mathrm{O}_{3}$ exposure; two-way ANOVA interaction effect of sex (c) and exposure (d), for JAK2 expression and sex (f) and exposure (g), for JAK2 phosphorylated (Y1007+Y1008) expression. Right panels: h Representative Western blot images of JAK2 and JAK2 phosphorylated (Y1007+Y1008) expression in estrous cycle stages of females, with filter air and $\mathrm{O}_{3}$ exposure; univariate analysis of $\mathbf{i}$ JAK2 and I JAK2 phosphorylated (Y1007+Y1008), expression in estrous cycle stages of females, with FA and $\mathrm{O}_{3}$ exposure. Two-way ANOVA interaction effect of exposure $\left.\mathbf{j}\right)$ and estrous cycle stages $(\mathbf{k})$, for JAK2 expression and exposure (m) and estrous cycle stages (n) and for JAK2 phosphorylated (Y1007+Y1008) expression. Univariate analysis data expressed as Ranks-Kruskal-Wallis test of densitometric analysis; the values are depicted as mean with SD, where ${ }^{*} p \leq 0.05$ and ${ }^{* *} p \leq 0.01$ are the levels of statistical significance compared to controls $(n=6-8$ per group). Two-way ANOVA for JAK2 and JAK2 phosphorylated (Y1007+Y1008) analysis is given in Tables 7 and 8, respectively

with Bonferroni adjustment revealed statistically significant difference in phosphorylated JAK2 expression score between filter air and ozone exposure. Ozone-exposed female had significant increase in the phosphorylated JAK2 expression score of 1.122 (95\% CI, 0.779 to 1.465$)$ points compared to the ozone-exposed males, $F(1,52)=43.108$, $p=<0.0005$, partial $\eta 2=0.453$ (Table 8) whereas females with ozone exposure had significant increase in the phosphorylated JAK2 score of 1.538 (95 \% CI, 1.195 to 1.881) points compared to the females exposed to the filter air, $F(1,52)=80.967, p=<0.0005$, partial $\eta 2=0.609$ (Table 8). Interaction effect of sex and exposure for JAK2 $\mathrm{p}-(\mathrm{Y} 1007+\mathrm{Y} 1008)$ expression is given in Fig. 3f, g.

However, as opposed to unphosphorylated JAK2, phosphorylated JAK2 (Y1007+Y1008) was found to have a higher and significant increase in females exposed to $\mathrm{O}_{3}$ in non-proestrus stages vs. females exposed in proestrus (Fig. 3h, l). Two-way ANOVA examining the effects of estrous cycle stages and filter air/ozone exposure showed statistically significant interaction $F(1,24)=$ 93.334, $p=<0.0005$, partial $\eta 2=0.795$. Simple main effects for estrous cycle stages and exposure type with Bonferroni adjustment revealed statistically significant difference in phosphorylated JAK2 expression score. Ozone-exposed non-proestrus females had significant increase in the phosphorylated JAK2 score of 1.965 (95\% CI, 1.710 to 2.220) points compared to the non-proestrus females exposed to the filter air, $F(1,24)=253.484, p=<0.0005$, partial $\eta 2=0.914$ (Table 8). Similarly, non-proestrus female exposed to ozone had significant increase in the phosphorylated JAK2 score of 1.578 (95\% CI, 1.324 to 1.883) points compared to the ozone-exposed proestrus

Table 7 Two-way ANOVA for univariate and pairwise comparisons between gender, estrous cycle stages, and exposure for JAK2 expression Univariate tests: dependent variable: JAK2

\begin{tabular}{|c|c|c|c|c|c|c|}
\hline & & & $d f$ & F & Sig. & Partial \\
\hline \multirow[t]{4}{*}{ Analysis of gender and exposure } & \multirow[t]{2}{*}{ Exposure } & FA & 1,52 & 0.890 & 0.350 & 0.017 \\
\hline & & Ozone & 1,52 & 1190.01 & $<0.0005$ & 0.958 \\
\hline & \multirow[t]{2}{*}{ Sex } & $\mathrm{F}$ & 1,52 & 972.745 & $<0.0005$ & 0.949 \\
\hline & & M & 1,52 & 18.071 & $<0.0005$ & 0.258 \\
\hline \multirow{4}{*}{$\begin{array}{l}\text { Analysis of female estrous cycle } \\
\text { stages and exposure }\end{array}$} & \multirow[t]{2}{*}{ Estrous cycle stage } & Non-proestrus & 1,36 & 360.191 & $<0.0005$ & 0.909 \\
\hline & & Proestrus & 1,36 & 161.757 & $<0.0005$ & 0.818 \\
\hline & \multirow[t]{2}{*}{ Exposure } & FA & 1,36 & 147.012 & $<0.0005$ & 0.803 \\
\hline & & Ozone & 1,36 & 34.392 & $<0.0005$ & 0.489 \\
\hline
\end{tabular}

Pairwise comparisons: dependent variable: JAK2

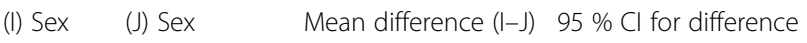

Analysis of gender and exposure Exposure

Analysis of female estrous cycle
stages and exposure Sex

FA
Ozone
F
M

$$
\begin{aligned}
& \text { M } \\
& \text { F } \\
& \text { Ozon } \\
& \text { FA } \\
& \text { OzOn }
\end{aligned}
$$

Proestrus Ozone

F

FA

$$
\text { Exposure }
$$

Ozone

$0.363 \quad 0.747$
Lower bound Upper bound $0.074 \quad 0.205$

$2.255 \quad 2.534$

$2.026 \quad 2.304$

$0.156 \quad 0.434$

$1.603 \quad 1.987$

$1.011 \quad 1.395$

$0.955 \quad 1.339$ 
Table 8 Two-way ANOVA for univariate and pairwise comparisons between gender, estrous cycle stages, and exposure for JAK2 phosphorylation (Y1007+Y1008) expression

\begin{tabular}{|c|c|c|c|c|c|c|}
\hline \multicolumn{7}{|c|}{ Univariate tests: dependent variable: JAK2 phosphorylated (Y1007+Y1008) } \\
\hline & & & $d f$ & $F$ & Sig. & Partial \\
\hline \multirow{4}{*}{$\begin{array}{l}\text { Analysis of gender and } \\
\text { exposure }\end{array}$} & \multirow[t]{2}{*}{ Exposure } & FA & 1,52 & 0.131 & 0.719 & 0.003 \\
\hline & & Ozone & 1,52 & 43.108 & $<0.0005$ & 0.453 \\
\hline & \multirow[t]{2}{*}{ Sex } & $\mathrm{F}$ & 1,52 & 80.967 & $<0.0005$ & 0.609 \\
\hline & & M & 1,52 & 4.290 & 0.043 & 0.076 \\
\hline \multirow{4}{*}{$\begin{array}{l}\text { Analysis of female estrous cycle } \\
\text { stages and exposure }\end{array}$} & \multirow{2}{*}{$\begin{array}{l}\text { Estrous cycle } \\
\text { stage }\end{array}$} & Non-proestrus & 1,24 & 253.484 & $<0.0005$ & 0.914 \\
\hline & & Proestrus & 1,24 & 5.101 & 0.033 & 0.175 \\
\hline & \multirow[t]{2}{*}{ Exposure } & FA & 1,24 & 0.764 & 0.391 & 0.031 \\
\hline & & Ozone & 1,24 & 163.543 & $<0.0005$ & 0.872 \\
\hline
\end{tabular}

Pairwise comparisons: dependent variable: JAK2 phosphorylated (Y1007+Y1008)

\begin{tabular}{|c|c|c|c|c|c|c|c|}
\hline & & & \multirow[t]{2}{*}{ (I) Sex } & \multirow[t]{2}{*}{ (J) Sex } & \multirow{2}{*}{$\begin{array}{l}\text { Mean difference } \\
(\mid-J)\end{array}$} & \multicolumn{2}{|c|}{$95 \%$ Cl for difference } \\
\hline & & & & & & $\begin{array}{l}\text { Lower } \\
\text { bound }\end{array}$ & $\begin{array}{l}\text { Upper } \\
\text { bound }\end{array}$ \\
\hline \multirow{4}{*}{$\begin{array}{l}\text { Analysis of gender and } \\
\text { exposure }\end{array}$} & \multirow[t]{2}{*}{ Exposure } & FA & M & $\mathrm{F}$ & 0.062 & 0.281 & 0.405 \\
\hline & & Ozone & $\mathrm{F}$ & M & 1.122 & 0.779 & 1.465 \\
\hline & \multirow[t]{2}{*}{ Sex } & $\mathrm{F}$ & Ozone & FA & 1.538 & 1.195 & 1.881 \\
\hline & & M & Ozone & FA & 0.354 & 0.011 & 0.697 \\
\hline \multirow{4}{*}{$\begin{array}{l}\text { Analysis of female estrous cycle } \\
\text { stages and exposure }\end{array}$} & \multirow{2}{*}{$\begin{array}{l}\text { Estrous cycle } \\
\text { stage }\end{array}$} & Non-proestrus & Ozone & FA & 1.965 & 1.710 & 2.220 \\
\hline & & Proestrus & Ozone & FA & 0.279 & 0.024 & 0.534 \\
\hline & \multirow[t]{2}{*}{ Exposure } & FA & Proestrus & Non-proestrus & 0.108 & 0.147 & 0.363 \\
\hline & & Ozone & Non-proestrus & Proestrus & 1.578 & 1.324 & 1.833 \\
\hline
\end{tabular}

female, $F(1,24)=163.543, p=<0.0005$, partial $\eta 2=0.872$ (Table 8). Filter air/ozone exposure on each sex alone and estrous cycle type alone in relation to the phosphorylated JAK2 is given in Table 8. Interaction effect of exposure and estrous cycle stages for JAK2 p-(Y1007+Y1008) expression is given in Fig. 3m, n.

\section{Ozone-associated lung inflammation and expression of NF-KB (p105/p50)}

$\mathrm{NF}-\mathrm{kB}$ activation is widely implicated in inflammatory conditions and is also known to possess cross-talk with pathways that may influence IL-6 expression. IL-6 via STAT3 transcription effector mediates local vascular macrophage activation in lungs and protection from oxidative stress. In addition, the NF-kB-IL-6 signaling pathway plays multiple roles in initiating and sustaining vascular inflammation. Assessment of NF- $\mathrm{KB}$ expression in our model showed sex differences in the lungs of mice exposed to $\mathrm{O}_{3}$ or FA. Ozone-exposed male mice showed a reduction in NF- $\mathrm{KB}$ expression, whereas females exposed to $\mathrm{O}_{3}$ had a significant increase in the NF-kB expression (Fig. 4a, b). However, due to sheer increase in the expression of NF- $\mathrm{kB}$ in females, pooling male and female data together masked the decrease in the expression in males, and an overall increase in expression was found with $\mathrm{O}_{3}$ exposure (Additional file 1: Figure S1-h). Two-way ANOVA on the sex and ozone/filter air exposure showed statistically significant interaction $F(1,52)=266.435, p=<0.0005$, partial $\eta 2=0.837$. Analysis of simple main effects for sex and exposure type with Bonferroni adjustment revealed statistically significant difference in NF-kB (p105/p50) expression score between filter air and ozone exposure. Ozone-exposed female had significant increase in the NF-kB (p105/p50) expression score of 0.970 (95\% CI, 0.855 to 1.085) points compared to the ozone-exposed males, $F(1,52)=$ 287.977, $p=<0.0005$, partial $\eta 2=0.847$ (Table 9), whereas females with ozone exposure had significant increase in the NF- $\mathrm{kB}$ (p105/p50) score of 1.056 (95\% CI, 0.941 to 1.170) points compared to the females exposed to the filter air, $F(1,52)=341.072, p=<0.0005$, partial $\eta 2=0.868$ (Table 9). Interaction effect of sex and exposure for NF-kB expression is given in Fig. 4c, d.

Univariate analysis of females exposed in different estrous cycle stages showed no overall difference in the expression patterns of the NF- $\mathrm{kB}$ with $\mathrm{O}_{3}$ exposure, compared to the matched controls exposed to the FA (Fig. 4e, f). Examining the effects of estrous cycle stages and filter air/ozone exposure through two-way ANOVA also showed statistically insignificant interaction $F(1,32)=$ 
a

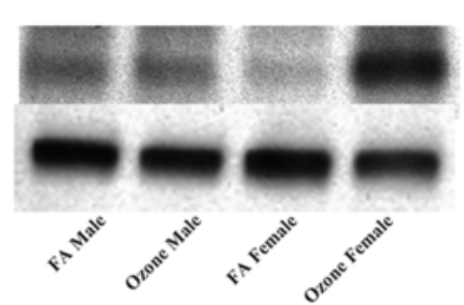

b
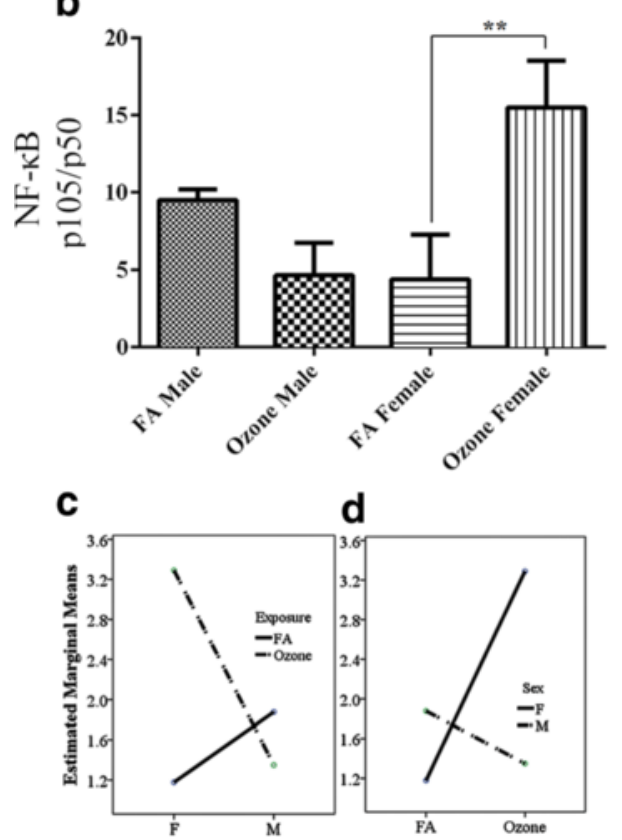

e $\mathrm{NF}-\mathrm{kB}$
$\mathrm{p} 105 / \mathrm{p} 50$

GAPDH

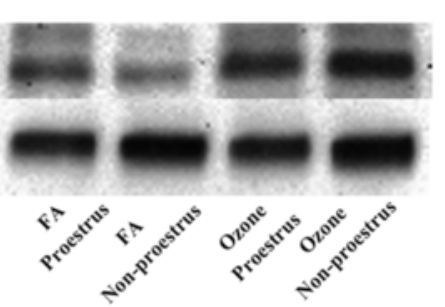

f

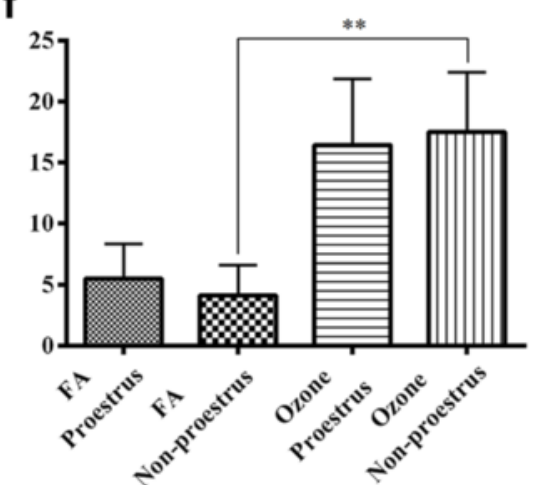

g h

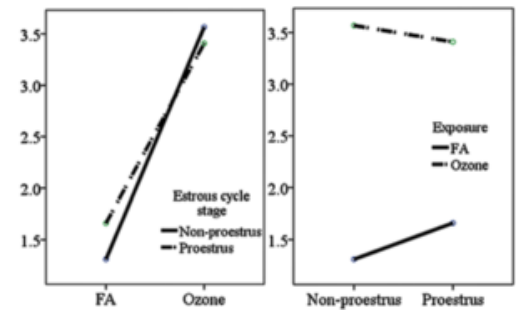

Fig. 4 NF-kB (p105/p50) expression and effect of ozone exposure. Left panel: a Representative Western blot images of NF-kB (p105/p50) expression in males and females with filter air and $\mathrm{O}_{3}$ exposure; $\mathbf{b}$ univariate analysis of NF-kB (p105/p50) expression in males and females with $\mathrm{FA}$ and $\mathrm{O}_{3}$ exposure; two-way ANOVA interaction effect of sex (c) and exposure (d) for NF-KB (p105/p50) expression. Right panel: e Representative Western blot images of NF-KB (p105/p50) expression in estrous cycle stages of females, with filter air and $\mathrm{O}_{3}$ exposure; $\boldsymbol{f}$ univariate analysis of NF-kB (p105/p50) expression in estrous cycle stages of females with $\mathrm{FA}$ and $\mathrm{O}_{3}$ exposure. Two-way ANOVA interaction effect of exposure (g) and estrous cycle stages (h) for NF- $\mathrm{KB}$ (p105/p50) expression. Univariate analysis data expressed as Ranks-Kruskal-Wallis test of densitometric analysis; the values are depicted as mean with $\mathrm{SD}$, where ${ }^{* *} p \leq 0.01$ is the level of statistical significance compared to controls ( $n=6-8$ per group). Two-way ANOVA for NF-kB (p 105/p50) expression analysis is given in Table 9

3.774, $p=<0.061$, partial $\eta 2=0.105$. Simple main effects for estrous cycle stages and exposure type with Bonferroni adjustment revealed statistically significant difference in NF-kB expression score. Ozone-exposed non-proestrus females had significant increase in the NF- $\mathrm{kB}$ score of 1.129 (95\% CI, 0.940 to 1.318) points compared to the non-proestrus females exposed to the filter air, $F(1,32)=$ 148.459, $p=<0.0005$, partial $\eta 2=0.823$ (Table 9). Similarly, proestrus female exposed to filter had insignificant increase in the NF- $\mathrm{kB}$ score of 0.175 (95\% CI, 0.013 to 0.363) points compared to the filtered air-exposed non-proestrus female, $F(1,32)=3.581, p=0.068$, partial $\eta 2=0.101$ (Table 9). Filter air/ozone exposure on each sex alone and estrous cycle type alone in relation to the NF- $\mathrm{kB}$ is given in Table 9. Interaction effect of exposure and estrous cycle stages for NF- $\mathrm{kB}$ expression is given in Fig. 4g, h.

\section{Ozone-associated lung inflammation and expression of AKT1}

Studies have documented that IL-6/STAT3 signaling can regulate AKT1 activation and that both JAK2 and AKT1 may play role in the activation of NF- $\mathrm{kB}[48,49]$. Initially believed to operate as components of distinct signaling pathways, several studies have demonstrated that the NF- $\mathrm{kB}$ and AKT1 signaling pathways can converge and play a crucial role in stress responses and inflammation [50]. In our experimental model, ozone exposure in pooled male and female mice resulted in no differences in AKT1 expression compared to animals exposed to FA (Additional file 1: Figure S1i). However, analysis of sex differences in lung AKT1 levels in response to $\mathrm{O}_{3}$ exposure depicted a marked decrease in males compared to matched controls exposed to FA, while females exposed to $\mathrm{O}_{3}$ showed a significant increase vs. FA (Fig. 5a, b). 
Table 9 Two-way ANOVA for univariate and pairwise comparisons between gender, estrous cycle stages, and exposure for NF-kB (p105/p50) expression

\begin{tabular}{|c|c|c|c|c|c|c|c|}
\hline \multicolumn{8}{|c|}{ Univariate tests: dependent variable: NF-kB (p105/p50) } \\
\hline & & & $d f$ & F & Sig. & \multicolumn{2}{|c|}{ Partial 2} \\
\hline \multirow{4}{*}{$\begin{array}{l}\text { Analysis of gender and } \\
\text { exposure }\end{array}$} & \multirow[t]{2}{*}{ Exposure } & FA & 1,52 & 37.382 & $<0.0005$ & \multicolumn{2}{|l|}{0.418} \\
\hline & & Ozone & 1,52 & 287.977 & $<0.0005$ & \multicolumn{2}{|l|}{0.847} \\
\hline & \multirow[t]{2}{*}{ Sex } & $\mathrm{F}$ & 1,52 & 341.072 & $<0.0005$ & \multicolumn{2}{|l|}{0.868} \\
\hline & & M & 1,52 & 21.306 & $<0.0005$ & \multicolumn{2}{|l|}{0.291} \\
\hline \multirow{4}{*}{$\begin{array}{l}\text { Analysis of female estrous cycle } \\
\text { stages and exposure }\end{array}$} & \multirow{2}{*}{$\begin{array}{l}\text { Estrous cycle } \\
\text { stage }\end{array}$} & Non-proestrus & 1,32 & 148.459 & $<0.0005$ & \multicolumn{2}{|l|}{0.823} \\
\hline & & Proestrus & 1,32 & 89.059 & $<0.0005$ & \multicolumn{2}{|l|}{0.736} \\
\hline & \multirow[t]{2}{*}{ Exposure } & FA & 1,32 & 3.581 & 0.068 & \multicolumn{2}{|l|}{0.101} \\
\hline & & Ozone & 1,32 & 0.731 & 0.399 & \multicolumn{2}{|l|}{0.022} \\
\hline \multicolumn{8}{|c|}{ Pairwise comparisons: dependent variable: NF-kB (p105/p50) } \\
\hline & & & \multirow[t]{2}{*}{ (I) Sex } & \multirow[t]{2}{*}{ (J) Sex } & \multirow{2}{*}{$\begin{array}{l}\text { Mean difference } \\
(I-J)\end{array}$} & \multicolumn{2}{|c|}{$95 \%$ Cl for difference } \\
\hline & & & & & & $\begin{array}{l}\text { Lower } \\
\text { bound }\end{array}$ & $\begin{array}{l}\text { Upper } \\
\text { bound }\end{array}$ \\
\hline \multirow{4}{*}{$\begin{array}{l}\text { Analysis of gender and } \\
\text { exposure }\end{array}$} & \multirow[t]{2}{*}{ Exposure } & FA & M & $\mathrm{F}$ & 0.349 & 0.235 & 0.464 \\
\hline & & Ozone & $\mathrm{F}$ & M & 0.970 & 0.855 & 1.085 \\
\hline & \multirow[t]{2}{*}{ Sex } & $\mathrm{F}$ & Ozone & FA & 1.056 & 0.941 & 1.170 \\
\hline & & M & FA & Ozone & 0.264 & 0.149 & 0.379 \\
\hline \multirow{4}{*}{$\begin{array}{l}\text { Analysis of female estrous cycle } \\
\text { stages and exposure }\end{array}$} & \multirow{2}{*}{$\begin{array}{l}\text { Estrous cycle } \\
\text { stage }\end{array}$} & Non-proestrus & Ozone & FA & 1.129 & 0.940 & 1.318 \\
\hline & & Proestrus & Ozone & FA & 0.874 & 0.686 & 1.063 \\
\hline & \multirow[t]{2}{*}{ Exposure } & FA & Proestrus & Non-proestrus & 0.175 & 0.013 & 0.364 \\
\hline & & Ozone & Non-proestrus & Proestrus & 0.079 & .110 & 0.268 \\
\hline
\end{tabular}

Two-way ANOVA on the sex and ozone/filter air exposure showed statistically significant interaction $F(1,52)=$ $60.730, p=<0.0005$, partial $\eta 2=0.539$. Analysis of simple main effects for sex and exposure type with Bonferroni adjustment revealed statistically significant difference in AKT1 expression score between filter air and ozone exposure. Ozone-exposed female had significant increase in the AKT1 expression score of 0.919 (95\% CI, 0.751 to 1.086$)$ points compared to the ozone-exposed males, $F(1,52)=121.354, p=<0.0005$, partial $\eta 2=0.70$ (Table 10) whereas females with ozone exposure had significant increase in the AKT1 score of 0.670 (95\% CI, 0.503 to 0.837 ) points compared to the females exposed to the filter air, $F(1,52)=64.526, p=<0.0005$, partial $\eta 2=0.554$ (Table 10). Interaction effect of sex and exposure for AKT1 expression is given in Fig. $5 \mathrm{c}$, d.

Examination of lung AKT1 levels in females exposed to $\mathrm{O}_{3}$ at different stages of the estrous cycle showed an increased expression in animals exposed in both proestrus and non-proestrus, but only females exposed in proestrus had a significant increase in AKT1 (Fig. 5e, f). The effects of estrous cycle stages and filter air/ozone exposure through two-way ANOVA also showed statistically significant interaction $F(1,24)=42.745, p=<$ 0.0005 , partial $\eta 2=0.639$. Simple main effects for estrous cycle stages and exposure type with Bonferroni adjustment revealed statistically significant difference in AKT1 expression score. Ozone-exposed proestrus females had significant increase in the AKT1 score of 1.892 (95\% CI, 1.719 to 2.065$)$ points compared to the proestrus females exposed to the filter air, $F(1,24)=511.045, p=<0.0005$, partial $\eta 2=0.955$ (Table 10). Similarly, proestrus female exposed to ozone had significant increase in the AKT1 score of 0.620 (95\% CI, 0.448 to 0.793 ) points compared to the ozone-exposed non-proestrus female, $F(1,24)=$ 54.923, $p=<0.0005$, partial $\eta 2=0.696$ (Table 10). Filter air/ozone exposure on each sex alone and estrous cycle type alone in relation to the AKT1 is given in Table 10. Interaction effect of exposure and estrous cycle stages for AKT1 expression is given in Fig. 5g, h.

\section{Discussion}

Innate immunity plays a critical role against infection and oxidative damage from inhaled air pollutants. Acute airway responses to inhaled ground-level $\mathrm{O}_{3}$ are characterized by recruitment of inflammatory cells to the lung epithelium and by the generation of inflammatory mediators including cytokines, chemokines, and adhesion molecules [51]. The specific mechanisms of $\mathrm{O}_{3}$ toxicity appear to be related to oxidation of cell membranes and 
a

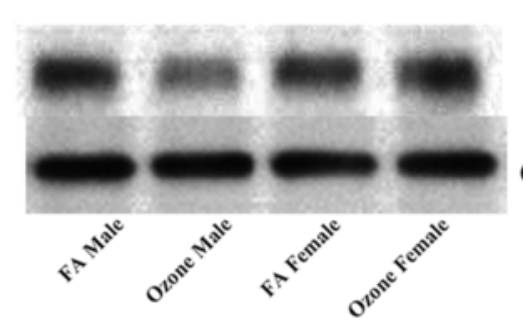

b

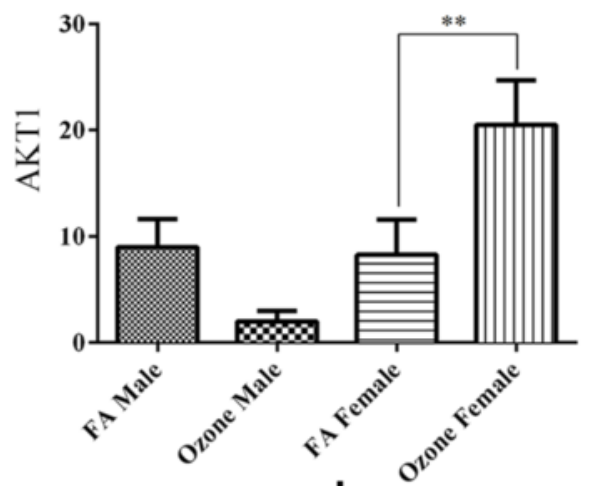

C

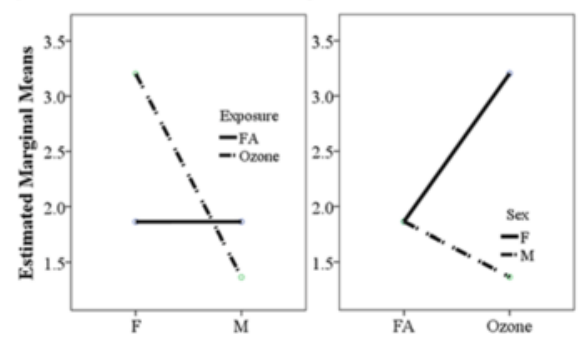

e

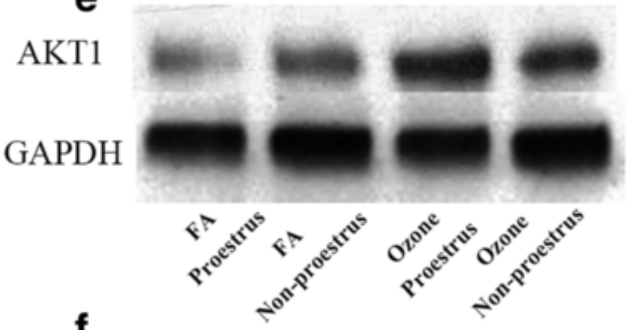

f

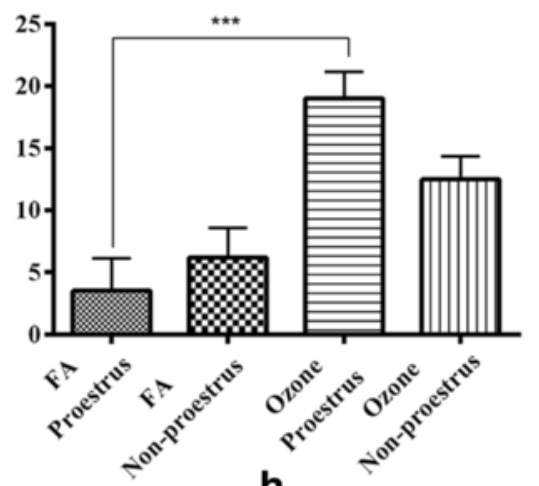

h

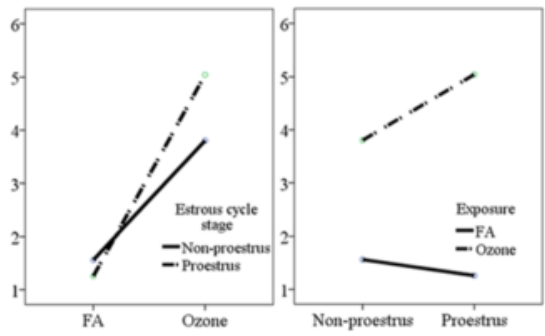

Fig. 5 AKT1 expression and effect of ozone exposure. Left panel: a Representative Western blot images of AKT1 expression in males and females with filter air and $\mathrm{O}_{3}$ exposure; $\mathbf{b}$ univariate analysis of AKT1 expression in males and females with $\mathrm{FA}$ and $\mathrm{O}_{3}$ exposure; two-way ANOVA interaction effect of sex (c) and exposure (d) for AKT1 expression. Right panels: e Representative Western blot images of AKT1 expression in estrous cycle stages of females, with filter air and $\mathrm{O}_{3}$ exposure; $\mathbf{f}$ univariate analysis of AKT1 expression in estrous cycle stages of females with $\mathrm{FA}$ and $\mathrm{O}_{3}$ exposure. Two-way ANOVA interaction effect of exposure $(\mathbf{g})$ and estrous cycle stages (h) for AKT1 expression. Univariate analysis data expressed as Ranks-Kruskal-Wallis test of densitometric analysis; the values are depicted as mean with SD where ${ }^{* *} p \leq 0.01$ and ${ }^{* * *} p \leq 0.001$ are the levels of statistical significance compared to controls ( $n=6-8$ per group). Two-way ANOVA for AKT1 expression analysis is given in Table 10

surfactant, resulting in lipid peroxidation and the production of reactive oxygen species [52]. The resulting oxidation products can prime alveolar macrophages and induce an increase in the production of pro-inflammatory cytokines that can result in injury of the lung epithelium, affecting its normal function and the overall lung innate immunity. Although studies have reported differential outcomes for lung disease triggered by ambient air pollution in men and women, the associated mechanisms of the immune response to $\mathrm{O}_{3}$ in the male and female lung remain unknown [53-55].

It has been known for years that the clinical course of inflammatory lung disease is highly influenced by sex, hormones, and the environment $[56,57]$. In our previous work, we demonstrated that expression of inflammatory mediators varies with sex in response to acute $\mathrm{O}_{3}$ exposure, indicating that fluctuating sex hormones levels may affect the immune response to environmental challenges [39]. Specifically, we reported differential mRNA expression levels of immune-related genes including pattern recognition receptors, transcription factors, and immune response mediators in the lungs of male and female mice exposed to $\mathrm{O}_{3}$ or FA, with significantly altered expression levels of neutrophilattracting chemokines, oxidative stress-related enzymes, and pro-inflammatory cytokines such as IL-6 [39]. Studies have indicated a complex and conflicting role for IL- 6 in the lung injury. Overexpression of IL-6 greatly reduces hyperoxic lung injury in the transgenic mice [58]. Similarly, in an aerosolized endotoxin model of lung injury, endogenous IL- 6 was found to be associated with decreased levels of TNF- $\alpha$, MIP-2, GM-CSF, IFNgamma, and airspace neutrophils and thereby exhibits a crucial anti-inflammatory function. On the contrary, various 
Table 10 Two-way ANOVA for univariate and pairwise comparisons between gender, estrous cycle stages and exposure for AKT1 expression

\begin{tabular}{|c|c|c|c|c|c|c|c|}
\hline \multicolumn{8}{|c|}{ Univariate tests: dependent variable: AKT1 } \\
\hline & & & $d f$ & F & Sig. & \multicolumn{2}{|l|}{ Partial 2} \\
\hline \multirow[t]{4}{*}{ Analysis of gender and exposure } & \multirow[t]{2}{*}{ Exposure } & FA & 1,52 & 0.001 & 0.996 & \multicolumn{2}{|l|}{0.002} \\
\hline & & Ozone & 1,52 & 121.354 & $<0.0005$ & \multicolumn{2}{|l|}{0.700} \\
\hline & \multirow[t]{2}{*}{ Sex } & $\mathrm{F}$ & 1,52 & 64.526 & $<0.0005$ & \multicolumn{2}{|l|}{0.554} \\
\hline & & M & 1,52 & 8.929 & 0.004 & \multicolumn{2}{|l|}{0.147} \\
\hline \multirow{4}{*}{$\begin{array}{l}\text { Analysis of female estrous cycle } \\
\text { stages and exposure }\end{array}$} & \multirow[t]{2}{*}{ Estrous cycle stage } & Non-proestrus & 1,24 & 179.278 & $<0.0005$ & \multicolumn{2}{|l|}{0.882} \\
\hline & & Proestrus & 1,24 & 511.045 & $<0.0005$ & \multicolumn{2}{|l|}{0.955} \\
\hline & \multirow[t]{2}{*}{ Exposure } & FA & 1,24 & 3.261 & 0.084 & \multicolumn{2}{|l|}{0.120} \\
\hline & & Ozone & 1,24 & 54.923 & $<0.0005$ & \multicolumn{2}{|l|}{0.696} \\
\hline \multicolumn{8}{|c|}{ Pairwise comparisons: dependent variable: AKT1 } \\
\hline & & & \multirow[t]{2}{*}{ (I) Sex } & \multirow[t]{2}{*}{ (J) Sex } & \multirow{2}{*}{$\begin{array}{l}\text { Mean difference } \\
(I-J)\end{array}$} & \multicolumn{2}{|c|}{$95 \%$ Cl for difference } \\
\hline & & & & & & Lower bound & Upper bound \\
\hline \multirow[t]{4}{*}{ Analysis of gender and exposure } & \multirow[t]{2}{*}{ Exposure } & FA & $\mathrm{F}$ & M & 0.001 & 0.167 & 0.168 \\
\hline & & Ozone & $\mathrm{F}$ & M & 0.919 & 0.751 & 1.086 \\
\hline & \multirow[t]{2}{*}{ Sex } & $\mathrm{F}$ & Ozone & FA & 0.670 & 0.503 & 0.837 \\
\hline & & M & FA & Ozone & 0.249 & 0.082 & 0.417 \\
\hline \multirow{4}{*}{$\begin{array}{l}\text { Analysis of female estrous cycle } \\
\text { stages and exposure }\end{array}$} & \multirow[t]{2}{*}{ Estrous cycle stage } & Non-proestrus & Ozone & FA & 1.121 & 0.948 & 1.293 \\
\hline & & Proestrus & Ozone & FA & 1.892 & 1.719 & 2.065 \\
\hline & \multirow[t]{2}{*}{ Exposure } & FA & Non-proestrus & Proestrus & 0.151 & 0.022 & 0.324 \\
\hline & & Ozone & Proestrus & Non-proestrus & 0.620 & 0.448 & 0.793 \\
\hline
\end{tabular}

other clinical and experimental studies establish deleterious function of IL-6 in acute lung injury. Clinical and animal studies both have suggested a role of IL- 6 in the pathogenesis of ventilator-associated lung injury [59-62]. Similarly, in a mouse sepsis model, IL-6 was found to be associated with increased mortality and increased lung complement 5a receptor expression [63]. IL- 6 plays an important and essential role in activating STAT transcription factors and thereby increases the recruitment of neutrophils in lung. In our animal model, we have previously demonstrated sex differences in the lung vascular permeability and polymorphonuclear neutrophil content in response to ozone exposure [39]. Marked increase in the neutrophil-attracting chemokines (Ccl20, $\mathrm{Cxcl} 5$, and $\mathrm{Cxcl} 2$ ) and pro-inflammatory cytokine IL-6 mRNAs with ozone exposure along with sex differences warrants further studies to examine the IL-6 and its sequential downstream pathways for mechanism of ozone-associated lung damage and higher susceptibility and severity of lung diseases in females. Better understating of the mechanism of the ozone-induced lung damage and sex differences will pave path for the research and discovery of therapeutic targets for patients with acute lung injury.

In this work, we have further characterized the acute lung immune response to $\mathrm{O}_{3}$ in the male and female lung at the intracellular level, by identifying sex-specific intracellular signaling associated with IL-6. We also evaluated a potential contribution of the estrous cycle to this regulation, in order to investigate whether circulating female hormones contribute to $\mathrm{O}_{3}$-induced inflammatory responses by modulating lung gene expression changes. Our results showed sex differences in protein expression and phosphorylation of various components of the IL-6/ IL-6R intracellular pathway and suggested a correlation of some of these with increases in pre-ovulatory hormone levels in the afternoon of proestrus. Because the lung expresses both estrogen and progesterone receptors, and these control alveolar loss and regeneration processes $[64,65]$, it is likely that ovarian hormones play a central role in lung inflammation and injury by modulating of immune gene expression [66]. In this regard, future studies using models of gonadectomy and hormone replacement will likely unveil the specific roles of sex hormones in the inflammatory response to $\mathrm{O}_{3}$.

Interleukin- 6 is secreted by immune cells and lung endothelial and epithelial cells in response to environmental insults $[67,68]$. This cytokine is known for its pleiotropic effects in mediating the pathogenesis, progression, and severity of various chronic lung diseases [69-71]. Binding of IL-6 to its receptor activates the signal transducing receptor glycoprotein 130 (gp130), inducing 
homodimerization and activation of Janus kinases (JAKs) that in turn activate signal transducers and activators of transcription (AKT1, NF-кB, STAT3) [72-74]. Phosphorylation of STAT3 allows for dimerization and nuclear translocation, where it can bind to specific elements in gene promoters and regulate their expression [75]. Our results strongly advocate for the co-existence of canonical and non-canonical STAT3 signaling mechanisms in the $\mathrm{O}_{3}$ induced oxidative lung damage (Fig. 6). A very minor alteration in the level of non-phosphorylated STAT3 in $\mathrm{O}_{3}$

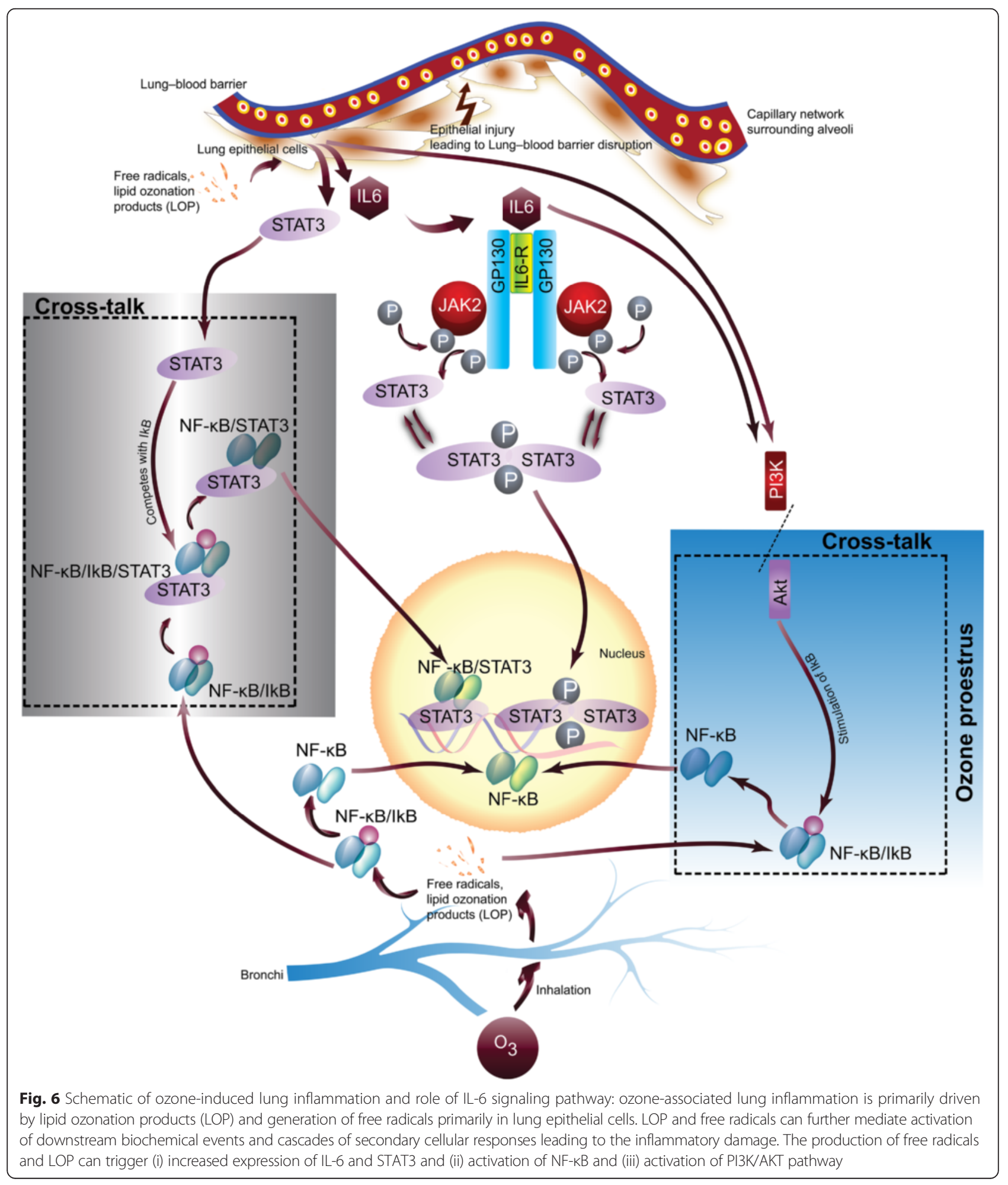


exposed males and lowering of the non-phosphorylated STAT3 in $\mathrm{O}_{3}$ exposed non-proestrus females is a suggestive of canonical mechanism of STAT3 nuclear translocation. Conversely, up-regulation of non-phosphorylated STAT3 in $\mathrm{O}_{3}$ exposed females in proestrus arguments for the non-canonical mechanism. Based on our results, we hypothesized that dual converging pathways which are acting synergistically in response to the level and type of hormones presented during the $\mathrm{O}_{3}$ insult dictate the inflammatory response and severity of the lung damage (Fig. 6). Our data suggest that $\mathrm{O}_{3}$ induced oxidative stress acts as a dual-edged sword for the dysfunction of the lung alveolar epithelial barrier and alveolar-capillary endothelial barrier. The oxidative damage by itself compromise the barrier function integrity and also in turn promote expression of increased levels of IL-6, STAT3, and NF-kB, and the resultant convergent trio-cascade may further deteriorate the barrier functionalities [68, 76] (Fig. 6).

Intracellular signaling mediated by STAT3 has been implicated in lung inflammation and in the pathogenesis of various lung diseases that affect men and women differentially [77, 78]. In this study, females displayed higher expression and/or phosphorylation of key elements of the IL-6R intracellular pathway, indicating that these mechanisms may mediate the observed increased inflammatory and cytokine gene expression previously reported by us in females vs. males [39]. In addition, our data indicate that the hormonal status of proestrus may predispose females to an increased inflammatory response to $\mathrm{O}_{3}$. Differential intracellular activation of JAK2/STAT3 and NF-kB/AKT1 pathways may be partially responsible for these effects (Fig. 6). In this regard, our study is the first to describe differential activation of these pathways in the lungs of male and female mice following acute $\mathrm{O}_{3}$ exposure, and the effects of hormonal status, as determined by the estrous cycle stage.

Studies have shown that $\mathrm{O}_{3}$, an air pollutant, can trigger allergic airway inflammation in women of reproductive age, and that these suffer more hospitalizations and death from asthma exacerbations than men [79, 80]. Since asthma complications occur at differential rates in women depending on their hormonal status (i.e., during the menstrual cycle, pregnancy, and menopause), and since these can be ameliorated with the use of oral contraceptives [20, 81, 82], it has been postulated that female sex hormones can act as physiological modulators of lung function and immunity in female patients. With the rise in the burden of inflammatory lung diseases in women worldwide, it is important to increase our knowledge of sex-specific mechanisms of immune response, as well as to understand the biological roles of sex hormones in modulating airway inflammation, innate immunity, and other processes relevant to the development and progression of these life-threatening conditions.

\section{Conclusions}

In conclusion, our data indicate a sex-specific IL-6 mediated inflammatory response to acute $\mathrm{O}_{3}$ exposure via involvement of JAK2/STAT3 and AKT1/NF-кB pathways and variations of this response with the estrous cycle stage in females. Our results show that the female IL-6 mediated acute inflammatory response to inhaled $\mathrm{O}_{3}$ is higher in females than in males and that activation of specific intracellular mechanisms in this response in females is dependent of the hormonal status of the animal. Our work contributes to the overall understanding of the physiopathology of lung disease triggered by environmental exposures and hormonal status in women. $\mathrm{Fu}$ ture studies will likely uncover points of intervention for lung disease therapies that will be specific for women and consider the hormonal status of the patient and facilitate the development of individualized medical treatments that are more efficient to treat lung inflammatory disease caused by air pollution.

\section{Additional file}

\begin{abstract}
Additional file 1: Figure S1. Analysis of (a) IL6, (b) IL6R, (c) STAT3, (d) STAT3-S727, (e) STAT3-Y705, (f) JAK2, (g) JAK2 phosphorylated (Y1007+Y1008), (h) NF-KB (p105/p50), and (i) AKT1 overall expression in animals exposed to FA and $\mathrm{O}_{3}$. Data expressed as Ranks-Kruskal-Wallis test of densitometric analysis; the values are depicted as mean with SD; here, ${ }^{* *} p \leq 0.01$ and ${ }^{* * * *} p \leq 0.0001$ are the levels of statistical significance compared to controls ( $n=6-8$ per group). (TIF $2773 \mathrm{~kb}$ )
\end{abstract}

Competing interests

The authors declare that they have no competing interests.

Authors' contributions

VM carried out the studies, performed the acquisition, analysis and interpretation of data, and helped PS in drafting the manuscript. SD helped VM for experimental setup and data acquisition. PS designed the whole project, supervised the execution of the experiments and data interpretation, and prepared the manuscript. All authors read and approved the final manuscript.

\section{Acknowledgements}

The authors also thank Dr. Joanna Floros and her staff for the assistance with the ozone exposure experiments.

\section{Grants}

Dr. Patricia Silveyra's research is supported by the Eunice Kennedy Shriver National Institute of Child Health and Human Development of the National Institutes of Health under BIRCWH award number K12HD055882 "Career Development Program in Women's Health Research at Penn State." The content is solely the responsibility of the authors and does not necessarily represent the official views of the $\mathrm{NIH}$.

Received: 11 September 2015 Accepted: 25 February 2016

Published online: 05 March 2016 


\section{References}

1. Organization WH. Health aspects of air pollution with particulate matter, ozone and nitrogen dioxide. Bonn, Germany: Report on a WHO working group; 2003. p. 13-5.

2. Bell ML, Peng RD, Dominici F. The exposure-response curve for ozone and risk of mortality and the adequacy of current ozone regulations. Environ Health Perspect. 2006;114(4):532-6.

3. Rice MB, Ljungman PL, Wilker EH, Gold DR, Schwartz JD, Koutrakis P, et al. Short-term exposure to air pollution and lung function in the Framingham Heart Study. Am J Respir Crit Care Med. 2013;188(11):1351-7.

4. Lim SS, Vos T, Flaxman AD, Danaei G, Shibuya K, Adair-Rohani H, et al. A comparative risk assessment of burden of disease and injury attributable to 67 risk factors and risk factor clusters in 21 regions, 1990-2010: a systematic analysis for the Global Burden of Disease Study 2010. Lancet. 2012;380(9859):2224-60.

5. Darrow LA, Klein M, Flanders WD, Mulholland JA, Tolbert PE, Strickland MJ. Air pollution and acute respiratory infections among children $0-4$ years of age: an 18-year time-series study. Am J Epidemiol. 2014;180(10):968-77.

6. Wong CM, Thach TQ, Chau PY, Chan EK, Chung RY, Ou CQ, et al. Part 4. Interaction between air pollution and respiratory viruses: time-series study of daily mortality and hospital admissions in Hong Kong. Res Rep. 2010; (154):283-362. http://www.ncbi.nlm.nih.gov/pubmed/21446214.

7. Goss CH, Newsom SA, Schildcrout JS, Sheppard L, Kaufman JD. Effect of ambient air pollution on pulmonary exacerbations and lung function in cystic fibrosis. Am J Respir Crit Care Med. 2004;169(7):816-21.

8. Samet JM. The Clean Air Act and health-a clearer view from 2011. N Engl J Med. 2011;365(3):198-201.

9. Pope CA, Muhlestein JB, May HT, Renlund DG, Anderson JL, Horne BD. Ischemic heart disease events triggered by short-term exposure to fine particulate air pollution. Circulation. 2006;114(23):2443-8.

10. Mudway IS, Kelly FJ. An investigation of inhaled ozone dose and the magnitude of airway inflammation in healthy adults. Am J Respir Crit Care Med. 2004;169(10):1089-95.

11. Sims EJ, Green MW, Mehta A. Decreased lung function in female but not male subjects with established cystic fibrosis-related diabetes. Diabetes Care. 2005;28(7):1581-7.

12. Caracta CF. Gender differences in pulmonary disease. Mt Sinai J Med. 2003;70(4):215-24

13. Falagas ME, Mourtzoukou EG, Vardakas KZ. Sex differences in the incidence and severity of respiratory tract infections. Respir Med. 2007;101(9):1845-63.

14. de Torres JP, Cote CG, Lopez MV, Casanova C, Diaz O, Marin JM, et al. Sex differences in mortality in patients with COPD. Eur Respir J. 2009;33(3):528-35.

15. Langhammer A, Johnsen R, Holmen J, Gulsvik A, Bjermer L. Cigarette smoking gives more respiratory symptoms among women than among men. The Nord-Trondelag Health Study (HUNT). J Epidemiol Community Health. 2000;54(12):917-22.

16. Langhammer A, Johnsen R, Gulsvik A, Holmen TL, Bjermer L. Sex differences in lung vulnerability to tobacco smoking. Eur Respir J. 2003;21(6):1017-23.

17. Martinez FJ, Curtis JL, Sciurba F, Mumford J, Giardino ND, Weinmann G, et al. Sex differences in severe pulmonary emphysema. Am J Respir Crit Care Med. 2007;176(3):243-52.

18. Varkey $A B$. Chronic obstructive pulmonary disease in women: exploring gender differences. Curr Opin Pulm Med. 2004;10(2):98-103.

19. Kanner RE, Connett JE, Altose MD, Buist AS, Lee WW, Tashkin DP, et al. Gender difference in airway hyperresponsiveness in smokers with mild COPD. The Lung Health Study. Am J Respir Crit Care Med. 1994;150(4):956-61.

20. Tam A, Morrish D, Wadsworth S, Dorscheid D, Man SF, Sin DD. The role of female hormones on lung function in chronic lung diseases. BMC Womens Health. 2011;11:24

21. Bouman A, Heineman MJ, Faas MM. Sex hormones and the immune response in humans. Hum Reprod Update. 2005;11(4):411-23.

22. Mikerov AN, Gan X, Umstead TM, Miller L, Chinchilli VM, Phelps DS, et al. Sex differences in the impact of ozone on survival and alveolar macrophage function of mice after Klebsiella pneumoniae infection. Respir Res. 2008:9:24.

23. Durrani F, Phelps DS, Weisz J, Silveyra P, Hu S, Mikerov AN, et al. Gonadal hormones and oxidative stress interaction differentially affects survival of male and female mice after lung Klebsiella pneumoniae infection. Exp Lung Res. 2011;38(4):165-72

24. Martinez-Lazcano JC, Gonzalez-Guevara E, del Carmen RM, Franco-Perez J, Custodio V, Hernandez-Ceron M, et al. The effects of ozone exposure and associated injury mechanisms on the central nervous system. Rev Neurosci. 2013;24(3):337-52
25. Postlethwait EM, Joad JP, Hyde DM, Schelegle ES, Bric JM, Weir AJ, et al. Three-dimensional mapping of ozone-induced acute cytotoxicity in tracheobronchial airways of isolated perfused rat lung. Am J Respir Cell Mol Biol. 2000;22(2):191-9.

26. Bergamaschi E, De Palma G, Mozzoni P, Vanni S, Vettori MV, Broeckaert F, et al. Polymorphism of quinone-metabolizing enzymes and susceptibility to ozone-induced acute effects. Am J Respir Crit Care Med. 2001;163(6):1426-31.

27. Wright DT, Adler KB, Akley NJ, Dailey LA, Friedman M. Ozone stimulates release of platelet activating factor and activates phospholipases in guinea pig tracheal epithelial cells in primary culture. Toxicol Appl Pharmacol. 1994;127(1):27-36.

28. McKinnon KP, Madden MC, Noah TL, Devlin RB. In vitro ozone exposure increases release of arachidonic acid products from a human bronchial epithelial cell line. Toxicol Appl Pharmacol. 1993;118(2):215-23.

29. Schlesinger RB, Driscoll KE, Gunnison AF, Zelikoff JT. Pulmonary arachidonic acid metabolism following acute exposures to ozone and nitrogen dioxide. J Toxicol Environ Health. 1990;31(4):275-90.

30. Devlin RB, McKinnon KP, Noah T, Becker S, Koren HS. Ozone-induced release of cytokines and fibronectin by alveolar macrophages and airway epithelial cells. Am J Physiol. 1994;266(6 Pt 1):L612-9.

31. Arsalane K, Gosset P, Vanhee D, Voisin C, Hamid Q, Tonnel AB, et al. Ozone stimulates synthesis of inflammatory cytokines by alveolar macrophages in vitro. Am J Respir Cell Mol Biol. 1995;13(1):60-8.

32. McKinney WJ, Jaskot RH, Richards JH, Costa DL, Dreher KL. Cytokine mediation of ozone-induced pulmonary adaptation. Am J Respir Cell Mol Biol. 1998;18(5):696-705

33. Junttila I, Meri S, Rämet M. Inflammasome-essential regulator of the inflammatory reaction. Duodecim. 2013;129(7):705-11.

34. Bhatia M, Zemans RL, Jeyaseelan S. Role of chemokines in the pathogenesis of acute lung injury. Am J Respir Cell Mol Biol. 2012;46(5):566-72.

35. Cho HY, Zhang LY, Kleeberger SR. Ozone-induced lung inflammation and hyperreactivity are mediated via tumor necrosis factor-alpha receptors. Am J Physiol Lung Cell Mol Physiol. 2001;280(3):L537-46.

36. Johnston RA, Schwartzman IN, Flynt L, Shore SA. Role of interleukin-6 in murine airway responses to ozone. Am J Physiol Lung Cell Mol Physiol. 2005;288(2):L390-7.

37. Zhao Q, Simpson LG, Driscoll KE, Leikauf GD. Chemokine regulation of ozone-induced neutrophil and monocyte inflammation. Am J Physiol. 1998; 274(1 Pt 1):L39-46.

38. Williams AS, Nath P, Leung SY, Khorasani N, McKenzie AN, Adcock IM, et al. Modulation of ozone-induced airway hyperresponsiveness and inflammation by interleukin-13. Eur Respir J. 2008;32(3):571-8.

39. Cabello N, Mishra V, Sinha U, DiAngelo SL, Chroneos ZC, Ekpa NA, et al. Sex differences in the expression of lung inflammatory mediators in response to ozone. Am J Physiol Lung Cell Mol Physiol. 2015;309(10):L1150-63. doi:10. 1152/ajplung.00018.2015.

40. Bassett D, Elbon-Copp C, Otterbein S, Barraclough-Mitchell H, Delorme M, Yang $\mathrm{H}$. Inflammatory cell availability affects ozone-induced lung damage. J Toxicol Environ Health A. 2001;64(7):547-65.

41. Chen B, Kan H. Air pollution and population health: a global challenge. Environ Health Prev Med. 2008;13(2):94-101.

42. Hollingsworth JW, Kleeberger SR, Foster WM. Ozone and pulmonary innate immunity. Proc Am Thorac Soc. 2007;4(3):240-6.

43. Kampa M, Castanas E. Human health effects of air pollution. Environ Pollut. 2008;151(2):362-7

44. Caligioni CS. Assessing reproductive status/stages in mice. Current protocols in neuroscience/editorial board, Jacqueline N Crawley [et al]. 2009; Appendix 4: Appendix 4l. doi: 10.1002/0471142301.nsa04is48.

45. Mikerov AN, Haque R, Gan X, Guo X, Phelps DS, Floros J. Ablation of SP-A has a negative impact on the susceptibility of mice to Klebsiella pneumoniae infection after ozone exposure: sex differences. Respir Res. 2008:9:77.

46. Haque R, Umstead TM, Ponnuru P, Guo X, Hawgood S, Phelps DS, et al. Role of surfactant protein-A (SP-A) in lung injury in response to acute ozone exposure of SP-A deficient mice. Toxicol Appl Pharmacol. 2007;220(1):72-82.

47. Silveyra $\mathrm{P}$, Catalano $\mathrm{P}$, Lux-Lantos $\mathrm{V}$, Libertun C. Impact of proestrous milieu on expression of orexin receptors and prepro-orexin in rat hypothalamus and hypophysis: actions of Cetrorelix and Nembutal. Am J Physio Endocrinol Metab. 2007;292(3):E820-8.

48. Hussain AR, Ahmed SO, Ahmed M, Khan OS, Al Abdulmohsen S, Platanias LC, et al. Cross-talk between NFkB and the PI3-kinase/AKT pathway can be targeted in primary effusion lymphoma (PEL) cell lines for efficient apoptosis. PLoS One. 2012;7(6):e39945. 
49. Gao H, Guo RF, Speyer CL, Reuben J, Neff TA, Hoesel LM, et al. Stat3 activation in acute lung injury. J Immunol. 2004;172(12):7703-12.

50. Hoesel B, Schmid JA. The complexity of NF-KB signaling in inflammation and cancer. Mol Cancer. 2013;12:86.

51. Kelly FJ, Fussell JC. Air pollution and airway disease. Clin Exp Allergy. 2011; 41(8):1059-71.

52. Connor AJ, Laskin JD, Laskin DL. Ozone-induced lung injury and sterile inflammation. Role of toll-like receptor 4. Exp Mol Pathol. 2012;92(2):229-35.

53. Gabriel G, Arck PC. Sex, immunity and influenza. J Infect Dis. 2014;209 Suppl 3:S93-9.

54. Kamil F, Pinzon I, Foreman MG. Sex and race factors in early-onset COPD. Curr Opin Pulm Med. 2013;19(2):140-4.

55. Rivera MP. Lung cancer in women: differences in epidemiology, biology, histology, and treatment outcomes. Semin Respir Crit Care Med. 2013; 34(6):792-801.

56. Straub RH. The complex role of estrogens in inflammation. Endocr Rev. 2007;28(5):521-74.

57. Vinikoor-Imler LC, Owens EO, Nichols JL, Ross M, Brown JS, Sacks JD. Evaluating potential response-modifying factors for associations between ozone and health outcomes: a weight-of-evidence approach. Environ Health Perspect. 2014;122(11):1166-76.

58. Waxman AB, Kolliputi N. IL-6 protects against hyperoxia-induced mitochondrial damage via $\mathrm{Bcl}$-2-induced Bak interactions with mitofusins. Am J Respir Cell Mol Biol. 2009;41(4):385-96.

59. Parsons PE, Eisner MD, Thompson BT, Matthay MA, Ancukiewicz M, Bernard $G R$, et al. Lower tidal volume ventilation and plasma cytokine markers of inflammation in patients with acute lung injury. Crit Care Med. 2005;33(1):1-6. discussion 230-2

60. Ranieri VM, Suter PM, Tortorella C, De Tullio R, Dayer JM, Brienza A, et al. Effect of mechanical ventilation on inflammatory mediators in patients with acute respiratory distress syndrome: a randomized controlled trial. JAMA. 1999;282(1):54-61.

61. Goldman JL, Sammani S, Kempf C, Saadat L, Letsiou E, Wang T, et al. Pleiotropic effects of interleukin-6 in a "two-hit" murine model of acute respiratory distress syndrome. Pulm Circ. 2014;4(2):280-8.

62. Ko YA, Yang MC, Huang HT, Hsu CM, Chen LW. NF-kappaB activation in myeloid cells mediates ventilator-induced lung injury. Respir Res. 2013;14:69.

63. Riedemann NC, Neff TA, Guo RF, Bernacki KD, Laudes IJ, Sarma JV, et al. Protective effects of IL- 6 blockade in sepsis are linked to reduced C $5 \mathrm{a}$ receptor expression. J Immunol. 2003;170(1):503-7.

64. Massaro D, Massaro GD. Estrogen regulates pulmonary alveolar formation, loss, and regeneration in mice. Am J Physiol Lung Cell Mol Physiol. 2004; 287(6):L1154-9.

65. Massaro D, Clerch LB, Massaro GD. Estrogen receptor-alpha regulates pulmonary alveolar loss and regeneration in female mice: morphometric and gene expression studies. Am J Physiol Lung Cell Mol Physiol. 2007; 293(1):L222-8.

66. Gilliver SC. Sex steroids as inflammatory regulators. J Steroid Biochem Mol Biol. 2010;120(2-3):105-15.

67. Hunter CA, Jones SA. IL-6 as a keystone cytokine in health and disease. Nat Immunol. 2015;16(5):448-57.

68. Yu M, Zheng $X$, Witschi H, Pinkerton KE. The role of interleukin- 6 in pulmonary inflammation and injury induced by exposure to environmental air pollutants. Toxicol Sci. 2002;68(2):488-97.

69. Rincon M, Irvin CG. Role of IL-6 in asthma and other inflammatory pulmonary diseases. Int J Biol Sci. 2012;8(9):1281-90.

70. Wedzicha JA, Seemungal TA, MacCallum PK, Paul EA, Donaldson GC, Bhowmik A, et al. Acute exacerbations of chronic obstructive pulmonary disease are accompanied by elevations of plasma fibrinogen and serum IL-6 levels. Thromb Haemost. 2000;84(2):210-5.

71. Carpagnano GE, Barnes PJ, Geddes DM, Hodson ME, Kharitonov SA. Increased leukotriene B4 and interleukin-6 in exhaled breath condensate in cystic fibrosis. Am J Respir Crit Care Med. 2003;167(8):1109-12.

72. Scheller J, Chalaris A, Schmidt-Arras D, Rose-John S. The pro- and antiinflammatory properties of the cytokine interleukin-6. Biochim Biophys Acta. 2011;1813(5):878-88

73. Hirano T, Ishihara K, Hibi M. Roles of STAT3 in mediating the cell growth, differentiation and survival signals relayed through the IL-6 family of cytokine receptors. Oncogene. 2000;19(21):2548-56.
74. Heinrich PC, Behrmann I, Müller-Newen G, Schaper F, Graeve L. Interleukin6-type cytokine signalling through the gp130/Jak/STAT pathway. Biochem J. 1998;334(Pt 2):297-314.

75. Jones SA, Horiuchi S, Topley N, Yamamoto N, Fuller GM. The soluble interleukin 6 receptor: mechanisms of production and implications in disease. FASEB J. 2001;15(1):43-58.

76. Sysol J, Belvitch P, Chen J, Machado R, Singla S. Hemin induces pulmonary endothelial cell barrier dysfunction via NFKB. Am J Respir Crit Care Med. 2015;191:A2075

77. Geraghty P, Wyman AE, Garcia-Arcos I, Dabo AJ, Gadhvi S, Foronjy R. STAT3 modulates cigarette smoke-induced inflammation and protease expression. Front Physiol. 2013;4:267

78. Li Y, Du H, Qin Y, Roberts J, Cummings OW, Yan C. Activation of the signal transducers and activators of the transcription 3 pathway in alveolar epithelial cells induces inflammation and adenocarcinomas in mouse lung. Cancer Res. 2007;67(18):8494-503.

79. McBride DE, Koenig JQ, Luchtel DL, Williams PV, Henderson Jr WR. Inflammatory effects of ozone in the upper airways of subjects with asthma. Am J Respir Crit Care Med. 1994;149(5):1192-7.

80. Yoda Y, Otani N, Sakurai S, Shima M. Acute effects of summer air pollution on pulmonary function and airway inflammation in healthy young women. J Epidemiol. 2014;24(4):312-20.

81. Hanley SP. Asthma variation with menstruation. Br J Dis Chest. 1981;75(3):306-8.

82. Pauli BD, Reid RL, Munt PW, Wigle RD, Forkert L. Influence of the menstrual cycle on airway function in asthmatic and normal subjects. Am Rev Respir Dis. 1989:140(2):358-62.

\section{Submit your next manuscript to BioMed Central and we will help you at every step:}

- We accept pre-submission inquiries

- Our selector tool helps you to find the most relevant journal

- We provide round the clock customer support

- Convenient online submission

- Thorough peer review

- Inclusion in PubMed and all major indexing services

- Maximum visibility for your research

Submit your manuscript at www.biomedcentral.com/submit 